\title{
On vocalic feature hierarchisation
}

\author{
Jørgen Staun \\ Department of English, University of Copenhagen, 84 Njalsgade, DK 2300, Copenhagen, Denmark
}

\section{Preliminaries}

It is now well-known that in what have often been termed the standard feature systems, cf. Jakobson et al. (1952), Chomsky and Halle (1968) and Ladefoged (1971), the phonological segment is viewed as an unordered bundle of feature specifications. It is equally well-known that this view of the phonological segment has been challenged in the decades following the proposal of these standard feature systems. Phonologists have argued that phonological rules often apply only to subsets of features or that features naturally belong in groups, and these facts are disguised if the feature matrix consists of unordered features. At least two substantial theories have defended the view of the segment that it should be organised in hierarchies or gestures. The two theories we have in mind are US-based feature geometry (e.g. Sagey, 1986; Halle, 1992; Clements, 1987, 1991) and European dependency phonology (e.g. Anderson and Jones, 1974, 1977; Anderson and Ewen, 1987; van der Hulst, 1994, 1995). The terms feature geometry and dependency phonology are here used to refer to more than one descriptive system. Feature geometry covers a wide range of proposals, all of which argue, in one or the other way, that features are hierarchically organised in feature trees with one feature at the top which then governs other features which may again govern more features with perhaps further features dependent on them. The term dependency phonology, as it is used here, is also a cover-term for several different proposals, but a somewhat more homogeneous set than that enclosed by the term feature geometry. The proposals enclosed by the term dependency phonology all share the fact that they make extensive use of the dependency relationship, which is used to express both segment-internal properties and external relations between units larger than the segment. The term dependency is also used in feature geometry, but here it refers to structural relations between feature hierarchies or between features and feature hierarchies, and not to the relation holding between the ultimate components. For this reason feature geometrical frameworks are not encompassed by the term dependency phonology.

E-mail address: staun@hum.ku.dk 
The reaction to such unstructured feature theories as the standard feature systems referred to above not only led to the organisation of features in hierarchies. The introduction of more structure segment-internally also resulted in a redefinition of the ultimate phonological components, so the latter are not always binary but also sometimes unary. The introduction of unary components does not follow naturally from the introduction of internal hierarchical structure, but during the process of organising features in hierarchies dependency phonologists developed the idea that in particular the vowel description would benefit from the phonological primitives being unary rather than binary or multivalued. This idea was further developed for the description of other parts of the internal structure of segments such as manner of articulation and initiation. Some versions of feature geometry have also adopted the unary components to describe in particular place of articulation. The obvious advantage of unary components surfaces when they are allowed to combine in dependency relationships. Such relationships express gradual properties in an obvious and intuitively natural way, something which is not available to a model employing for example binary features.

The present study will assess the applicability of the two types of hierarchical model, feature geometry and dependency phonology (the latter still used in a broad sense) with regard to the description of the phonology of vowels. We shall consider two versions within each type of model. Within feature geometry, we shall consider what will be referred to as the articulator-based version. An outline of this version can be found in Halle (1992), which follows the work of Sagey (1986). Articulator-based feature geometry employs binary features only and is thus closely akin to SPE or SPE-type of models. Because of its affinity with SPE, the articulator-based model will not receive as much attention as the second version of feature geometry to be considered here (SPE type of models have been assessed extensively elsewhere, see e.g. Lass and Anderson, 1975; Lass, 1984). We shall refer to this second version as stricture-based feature geometry. This version of feature geometry has primarily been developed by Clements $(1987,1991)$. Because of its different organisation of the feature tree, in particular its use of a feature node labelled 'stricture', this version of feature geometry has been referred to as stricture-based feature geometry.

The two versions of dependency phonology which will be assessed here are the standard dependency model as presented primarily by Anderson and Ewen (1987) with a few modifications, and the model known as CV phonology which has been developed by van der Hulst (1989, 1994, 1995). Applying the term dependency phonology to both these models involves a use of this term which is broader than is usually the case. Normally, dependency phonology refers only to the former of the two models just mentioned, and below we shall use the term in this more narrow sense again. But we apply the term to both at this introductory state because it is a characteristic property of both models that they employ unary components, $\mathrm{CV}$ phonology to a very radical degree, hypothesising only two unary components, $\mathrm{C}$ and $\mathrm{V}$, and because the components of either model may interact in dependency relationships. In this respect, the two models owe much to the early pioneering work of Anderson and Jones (1974, 1977).

The phonology of vowels provides the basis for the comparison between and evaluation of these two types of phonological representation. Thus the way the 
description of the vowel space is handled by these two types of model will be dealt with in some detail in the immediately following discussion. Once this has been established, and in this connection the main focus will be on stricture-based feature geometry and the two dependency-based models rather than articulator-based feature geometry, we shall consider some concrete phonological phenomena involving vowel height and vowel place in detail. In particular two types of phenomena will be discussed: phenomena involving secondary articulation and phenomena involving vowel harmony, and the applicability of each model will be tested against these phenomena. Lastly, as a way of providing a broader basis for our assessment of the two types of representational model, we will examine three phenomena, viz. a dissimilation, a vowel harmony and a consonant constraint, which have been claimed to constitute a problem for any model employing unary components.

\section{Preliminary remarks on feature hierarchisation}

Let us first review some of the fundamental hypotheses of the two types of hierarchical model. It is a fundamental hypothesis of both models that the phonological segments involve hierarchically ordered features or components. Although they differ with respect to the exact architecture of these hierarchies, both models agree on the following basic assumptions: (i) there exist higher-order units in terms of which lower-order units or features are organised; (ii) the higher-order units may be features or may be independent labels reflecting phonologically or phonetically based conflations of features or components; (iii) the ultimate constituents of the feature trees are a universal set of unary, binary or multivalued features or components.

European dependency phonology is the first phonological model to point out that feature matrices should contain hierarchically ordered features or components. In an early and very influential proposal this idea of the internal structure of a segment is presented as shown in (1) (cf. Lass and Anderson, 1975; Lass, 1976; Ewen, 1980):

$$
\begin{array}{ll}
\text { articulatory gesture } & {\left[\begin{array}{l}
{[\text { high }]} \\
{[\text { low }]} \\
{[\text { back }]} \\
{[\text { anterior }]} \\
\text { [coronal }]
\end{array}\right]} \\
\text { categorial gesture } & {\left[\begin{array}{l}
{[\text { sonorant }]} \\
\text { [consonantal }] \\
\text { [vocalic }] \\
{[\text { continuant }]} \\
{[\text { voice }]}
\end{array}\right]} \\
\text { initiatory gesture } & {\left[\begin{array}{l}
{[\text { stiff vf }]} \\
{[\text { slack vf }]} \\
{[\text { spread gl }]} \\
{[\text { constr gl }]}
\end{array}\right]}
\end{array}
$$


(1) does not represent an actual phonological segment, but merely illustrates the way the features are organised. The higher-order units in this framework (arranged to the left of the feature column) are called gestures which are all dependent on the root node. The gestures then organise the individual features in sub-segments which partake in phonological rules and constraints. For example, phenomena such as homorganicity or debuccalisation affect the articulatory gesture. Similarly, lenition or fortition phenomena can be shown to affect only the categorial gesture (for discussion see e.g. Lass, 1976; Ewen, 1980).

In subsequent works the organisation shown in (1) has been refined in such a way that gestures are allowed to interact or to have subgestures. Thus, in Anderson and Ewen (1987) the structure of the articulatory and categorial gestures are as shown in (2):

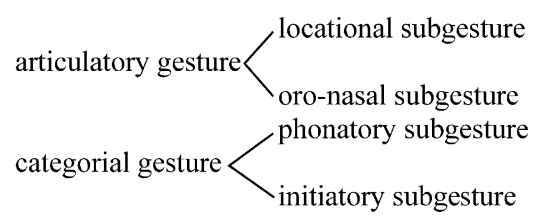

and the subgestures may interact in dependency relations. Furthermore, with the refinement shown in (2) unary components have replaced the binary (or sometimes multivalent) features which make up the matrices in the earliest proposals as shown in (1). A fundamental property of these components is not only their privativeness, i.e. that they are either present or absent, but also that they may enter into dependency relationships with one another as a way of describing phonological distinctions. This property and the fact that suprasegmental structure is also described in terms of dependency relations have led to the term dependency phonology.

The model of Anderson and Ewen has been further developed in the 1990s, specifically by van der Hulst (see also Staun, 1996). In his papers from 1995 and 1997, van der Hulst developed a radical version of dependency phonology whose architecture of gestures varies somewhat from the classical version and whose ultimate constituents amount to basically two unary components, $\mathrm{C}$ and V. His internal structure organisation is partly shown in (3):

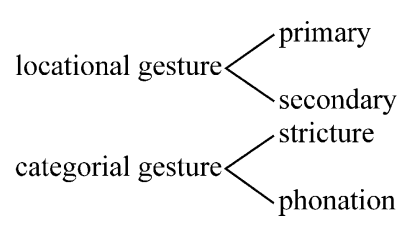

The ultimate constituents, $\mathrm{C}$ and $\mathrm{V}$, of each subgesture are not listed, but their interpretation depends on whether they describe the one or the other gesture. We shall investigate the appropriateness of this proposal further later.

In (4) we display how the same basic idea of segment structure is expressed in feature geometry. (4) shows the geometry outlined by Halle (1992), which follows 
the work of Sagey (1986). This is the version of feature geometry which was referred to earlier as articulator-based feature geometry:

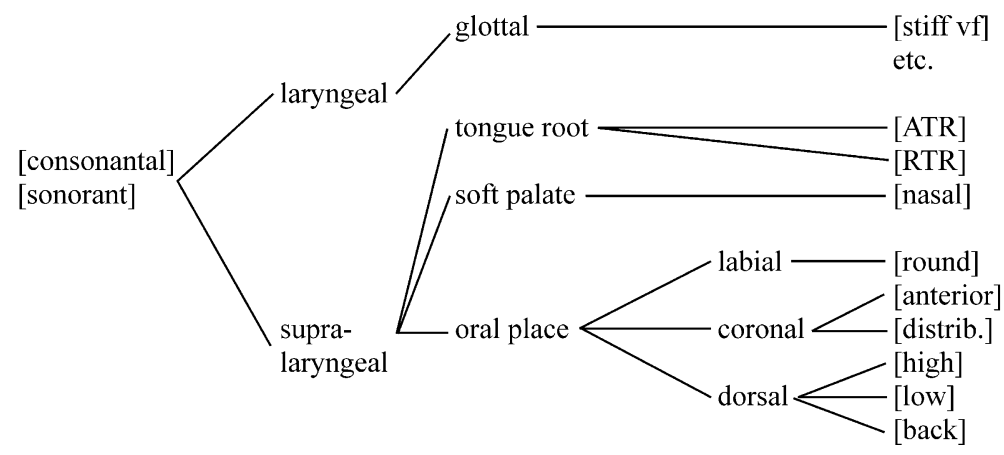

again this organisation is motivated by the way features group in phonological rules and constraints. As in the dependency proposals, feature geometry also uses labels which specify groups of features such as, for example, laryngeal, supralaryngeal, oral place.

How the architecture of features in (4) differs from the architecture of stricturebased feature geometry, the other version of feature geometry which we shall consider here, is irrelevant in the present context except for the part of the feature tree which concerns the description of vocalic place [see (5) later]. What is important to note is that although disagreement exists internally within what we broadly have termed dependency phonology and broadly have termed feature geometry, both types of hierarchical models agree on the necessity of having an independent hierarchy denoting place of articulation. In the former models this hierarchy is termed the articulatory gesture, and in feature geometry it is termed place. As shown in (1) and (4), this hierarchy subsumes any articulatory property which has to do with the location of a consonantal stricture or a vowel quality. Our business is now to assess the applicability of these two types of model with respect to the description of the phonology of vowels. Our first task must then be to specify how each type of model proposes to describe the vowel space.

\section{The vowel space}

\subsection{Proposals within feature geometry}

The feature organisation represented in (4) is based on the idea that oral place subsumes three active locations and that one of these, viz. dorsal, further determines the SPE-features [high], [low] and [back]. This articulator-based model is rivalled by stricture-based feature geometry, which as already pointed out, has been argued for by, among others, Clements (1991). The assumption of this version of feature geometry is that oral place is a sister node of a stricture or aperture node: stricture in the case of consonants and aperture in the case of vocoids. Thus the feature geometry varies 
according to whether the feature tree is headed by a V or a $\mathrm{C}$. This is illustrated in (5) (cf. Clements and Hume, 1995):

(5)

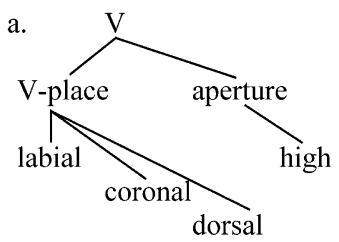

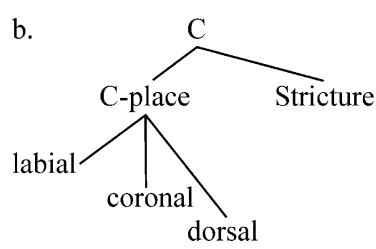

From the point of view of vowel description, articulator-based and stricture-based feature geometry [cf. (4) and (5), respectively] make different predictions. The articulator-based model outlined in (4) predicts that all vowels form a natural class with dorsal consonants, as [high], [low] and [back] hang from the dorsal node. The stricture-based model, on the other hand, specifies front vowels as [coronal] and back vowels as [dorsal]. Furthermore, it is also the implication of the stricture-based model that the old SPE feature [back] should be replaced by the two features [coronal] and [dorsal] and that these two features along with [labial] describe vowels and consonants alike. Finally, the two models make different transparency predictions. For example, the articulator-based model predicts that a vowel place feature cannot spread from one vowel to another across a dorsal consonant specified for the same feature. The stricture-based model, on the other hand, predicts that the spreading of such a vowel feature only fails to occur if the intervening consonant is specified for the $\mathrm{V}$-place feature that spreads. Such a V-place specification characterises only secondary articulations in consonants in the stricture-based model, as we shall see shortly.

The two models also differ with respect to the way they propose to account for vowel height. As pointed out, the major innovation of the stricture-based model is that vowel height is segregated from the other vocalic features and made to hang from an independent aperture node. The implication of this is that vowel height functions independently of the other vowel features and that - unlike in the articulator-based model - it is phonologically unrelated to dorsality (see also Odden, 1991). But the difference not only surfaces at the higher-order level. It is also manifested in the choice of features. In the stricture-based model, one feature suffices to capture vowel height, viz. the binary feature [open], which may be resolved in several rank-ordered tiers to allow for any number of vowel heights. By comparison, the articulator model employs the SPE-features [high] and [low] and as a consequence faces the problem (because [ + high + low] is an impossible specification) of having to invoke the problematical extra features [ATR] or [tense] when a vowel system with more than three vowel heights has to be accounted for. [tense] is often inappropriate because vowel length is not found in all languages, and the problem with [ATR] is that it is unclear whether its articulatory correlates, expansion of the pharynx, are appropriate for other vowel distinctions than those it was originally constructed to account for, viz. distinctions in vowel systems of some West African languages. Another and more serious problem is that [ATR] is an expansion of the node laryngeal [cf. (4)]. As such it cannot act together with the V-place features. 
Later we examine in more detail the implications of the feature organisation of these two models. But first we must consider the vowel place description as it appears within what we have termed dependency phonology which, it should be recalled, has been used here to comprise both classical dependency phonology and $\mathrm{CV}$ phonology. We shall consider the development of these two types of dependency-based descriptions. First we consider the original account of dependency phonology (cf. Anderson and Jones, 1974, 1977; Anderson and Ewen, 1987), then the two models inspired by dependency phonology, viz. partly the forerunner of CV phonology (cf. van der Hulst, 1989) and partly CV phonology itself (van der Hulst, 1994). Lastly we reconsider the original version of dependency phonology and propose some modifications to it in the light of van der Hulst's proposals.

\subsection{The first dependency-based description}

The alternative vowel space description which arose in the wake of Lass's and Lass and Anderson's proposals of feature organisation [cf. (1)] has as its main characteristic that the phonological primitives are unary particles or components. That they are unary means that they can be either present or absent. In other words, only one value counts, viz. presence of a component, unlike binary features whose plus as well as minus value can serve to characterise a sound or a class of sounds. As we shall see later, this limitation of the unary components will be compensated for by allowing negated components. Formulated in terms of a feature tree, the first system which arose looks as follows:

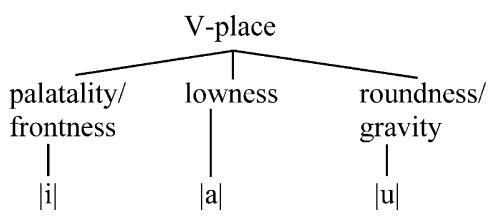

The three components which terminate this tree are based on the widely attested vowels, /i/, /a/ and /u/ (cf. Maddieson, 1984). In this model any vowel system is then described in terms of specifications in which one of these components either individually represents a vowel or in terms of specifications in which these components occur in structured combinations (we leave aside here the fourth component $|\boldsymbol{\partial}|$ centrality, but we return to it later). By structured combinations is meant combinations in which one or more components dominate or are dependent on one or more other components. A familiar vowel system like $/ \mathrm{i}, \mathrm{e}, \mathrm{a}, \mathrm{a}, \mathrm{o}, \mathrm{o}, \mathrm{u} /$ thus receives the following interpretation within this system, where $|i ; a|$, for example, means that the component $|i|$ dominates the component $|\mathrm{a}|$ (another way of representing this dominance relationship is in terms of ' $\rightarrow$ ' where the direction of the arrow specifies the direction of the dominance relationship):

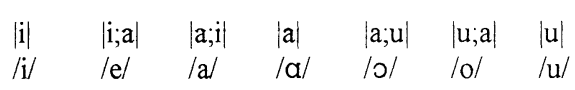


From (7) it is clear that front vowels are located on the $|\mathbf{i}|-|\mathrm{a}|$-'scale' and back vowels on the $|\mathbf{u}|-|\mathbf{a}|-$-'scale'. (7) also shows that the closer the vowel the less $|\mathbf{a}|$-ness it contains and the more open it is the more dominant this property is.

The pivotal notion in (7) is dependency. It is important to note that the term dependency is used in hierarchical descriptions to denote two relations. In dependency phonology, as in the earlier example, it denotes the relation a component enters into with one or more other components to describe the internal structure of a phonological segment, in particular it describes the relative preponderance of a specific property. In feature geometry, on the other hand, (cf. McCarthy, 1988) dependency denotes the structural relation which holds between a higher-order unit and the feature/component which branches off or hangs from such a high-order unit node. We shall refer to the first type of dependency as i-dependency (internal dependency) and we shall refer to the second type as s-dependency (structural dependency).

\subsection{The dependency description further developed}

The description of vowels based on dependency in the first sense, i.e. i-dependency, as outlined briefly in (7), has been criticised on two grounds (van der Hulst, 1989). Firstly, it has been argued that the three-way distinction between $|\mathrm{i}|,|\mathrm{u}|$ and $|\mathrm{a}|$ conflicts with the claim that phonological structure is binary. That is, the three branches in (6) should be restructured to involve two-way splits. This is the reason that van der Hulst adopts the following hierarchical organisation for the three components:

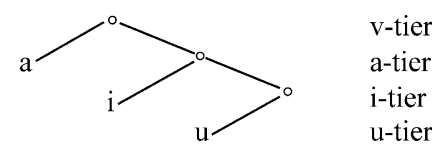

which separates $|\mathbf{a}|$, on the one hand, from $|\mathbf{i}|$ and $|\mathbf{u}|$, on the other. One empirical motivation for this split is that the spreading of $|\mathrm{i}|$ entails the spreading of $|\mathrm{u}|$. Another is the fact that it enables us to express the class of high vowels, as we shall return to shortly.

Secondly, van der Hulst has argued that it is not clear why $|\mathrm{i}|$ alone specifies [i] and why $|\mathrm{u}|$ alone specifies [u]. Given the definitions of these components, it is clear that $|\mathrm{i}|$ specifies a front vowel but not also automatically a high vowel. Similarly, it is clear that $|\mathrm{u}|$ alone specifies a back vowel but not also automatically a high vowel. To accommodate for this deficiency, van der Hulst proposes new interpretations of the three components depending on whether they act as governors or dependents (1989, p. 261):

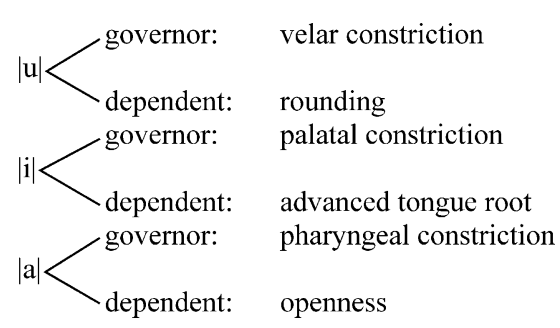


van der Hulst links these refined interpretations with a redundancy rule which states that it is natural for a component to occur both as governor and as dependent in a representation of a vowel. Thus $|\mathrm{i} ; \mathrm{i}||\mathrm{u} ; \mathrm{u}|$ and $|\mathrm{a} ; \mathrm{a}|$ are all possible representations. For example, the former two are used to distinguish between $/ \mathbf{i} / \sim / \mathbf{i} /$ and $/ \mathrm{u} / \sim / \mathrm{u} /$ as shown in (10):

$$
\begin{array}{llll}
/ \mathrm{i} / & / \mathrm{i} / & / \mathrm{u} / & / \mathrm{u} / \\
|\mathrm{i} ; \mathrm{i}| & |\mathrm{i}| & |\mathrm{u} ; \mathrm{u}| & |\mathrm{u}|
\end{array}
$$

The advantage of this refinement is that it does away with the component $|\partial|$, centrality, which in the classical version of dependency phonology (Anderson and Ewen, 1987) is used to describe, among other vowels, $/ \mathbf{i} /$ and $/ \mathrm{u} /$. The disadvantages are that the more complex vowels $/ \dot{i} /$ and /u/ now appear as the least complex having two and not one component in their representations, and that it is not obvious that $|\mathrm{i}|,|\mathrm{u}|$ and $|\mathrm{a}|$ are 'atomic' components, when each can, as it were, be split up into two subcomponents.

van der Hulst subsequently develops a more accurate interpretation of the three components than that of (9) in terms of the hierarchy given in (8). Firstly, the components are assigned intrinsic interpretations which are the same as those in (8), except that $|\mathrm{u}|$ is only assigned the feature 'round'. Secondly, due to their structural position in the hierarchy in (8), the components are assigned extrinsic interpretations. To associate with the top-most tier, the v-tier, the components $|\mathbf{i}|$ and $|\mathbf{u}|$ have to pass through higher tiers. As they pass through each tier, the extrinsic features of these tiers are activated. Exactly which features are activated depends on whether the component which passes through the tier in question is a dependent or a governor. If a dependent, the effect is that only the colour features but no location features are activated. If it is a governor both types of features are activated. (11) Presents an overview of the feature hierarchy resulting from the component hierarchy given in (8) ('con.' stands for constriction, 'rtr' for retracted tongue root and 'atr' for advanced tongue root):

\begin{tabular}{|c|c|c|c|}
\hline \multirow[b]{2}{*}{$|\mathrm{a}|$} & intrinsic features & \multicolumn{2}{|c|}{ extrinsic features } \\
\hline & $\begin{array}{l}\text { [pharyngeal con.] } \\
\text { [open] }\end{array}$ & $\begin{array}{l}\text { colour } \\
\text { [closed] }\end{array}$ & $\begin{array}{l}\text { location } \\
\text { [tongue body con.] }\end{array}$ \\
\hline |i| & $\begin{array}{l}\text { [palatal con.] } \\
\text { [ATR] }\end{array}$ & [RTR] & [velar con] \\
\hline$|\mathrm{u}|$ & [round] & (none) & (none) \\
\hline
\end{tabular}

Let us consider what affect these interpretations of the components have on, for example, the description of the contrast between $/ \mathrm{e} /$ and $/ \mathfrak{x} /$.

$$
\begin{array}{lll}
\text { /e/ } & \mathrm{i}[\mathrm{pal}, \mathrm{ATR}] & \mathrm{a} \text { [pharyngeal, open, closed] } \\
& \begin{array}{c}
\text { a [open, tongue body con] } \\
\text { [closed] }
\end{array} & \mathrm{i}[\text { ATR }]
\end{array}
$$


Consider also the interpretation of the vowels $/ \mathbf{i} /$ and $/ \mathrm{u} /$ discussed earlier. Since these are solely specified in terms of extrinsic features, no components will be present in their representations:

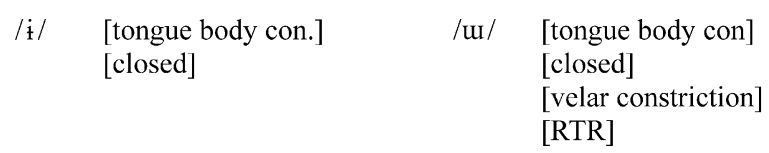

The idea of this descriptive system is then that the components contribute different features depending on whether they act as governors or dependents, as in the system in (9). The interpretation is also richer than this system. But it is not clear that it is also better. For example, it is not obvious that it is appropriate to interpret /e/ and $/ \mathfrak{x} /$ as being both [open] and [closed] at the same time. Similarly it not obvious that the rounded front vowels $/ y /$ and $/ \varnothing /$, as stipulated by van der Hulst (op. cit., p. 268), are appropriately described as containing the feature [RTR] and the feature [ATR] at the same time. Both [open] and [closed] and [ATR] and [RTR] are incompatible just like [high] and [low] are incompatible and [front] and [back] are incompatible. An advantage of this description, however, is that again it does away with the component $|\partial|$. But as in the description shown in (10), it is still a problem that in a vowel system which has both $/ \dot{i} /$ and $/ \mathrm{u} /$ and $/ \mathrm{i} /, / \mathrm{u} /$ and $/ \mathrm{a} /$ the latter three will receive more complex feature interpretations than the former two, despite the fact that the former are not the most widely occurring vowels.

Although individual parts of van der Hulst's description certainly constitutes an improvement, the overall impression is that it creates almost as many problems as it solves. In particular, the interpretation of the components as involving apparently incompatible feature specifications is problematical. Perhaps this explains why van der Hulst subsequently has developed a new phonological model (cf. van der Hulst, 1994, 1995) which has inherited the good parts of this quite complex description and which proposes new descriptions for others. This is the model which is known under the name of CV phonology.

\subsection{The CV-based description}

The most significant innovation of CV phonology is that just two components, $|\mathrm{C}|$ and $|\mathrm{V}|$, suffice to describe the internal structure of segments. For this to be possible, $|\mathrm{C}|$ and $|\mathrm{V}|$ must receive different interpretations depending on the hosting gesture and their relative preponderance in a dependency relation. The general interpretation of $|\mathrm{C}|$ and $|\mathrm{V}|$ are as follows (van der Hulst, 1995, p. 450):

\footnotetext{
$|C|: \quad$ denotes articulatory events which involve a relative high degree of closure, stricture or contraction

$|\mathrm{V}|$ : denotes the absence of the $|\mathrm{C}|$-type events, that is, a relative high degree of sonorancy
} 
Like in the standard version of dependency phonology, $|\mathrm{C}|$ and $|\mathrm{V}|$ may individually constitute a gesture or subgesture or they may combine in i-dependency relations. Thus the simplest representations look as in (15) (subscripts indicate dependent components):

$$
\begin{array}{llll}
|\mathrm{C}| & \left|\mathrm{C}_{\mathrm{V}}\right| & \left|\mathrm{V}_{\mathrm{c}}\right| & |\mathrm{V}|
\end{array}
$$

Moreover, these four representations may be used to compose further complex structures involving new i-dependency relations, but only such that a component cannot directly govern itself. According to van der Hulst, these complex representations may be V-headed or C-headed (op. cit., p. 451):

$$
\begin{array}{cccccccc}
\mathrm{C} & \mathrm{C} & \mathrm{C}_{\mathrm{V}} & \mathrm{C}_{\mathrm{V}} & \mathrm{V} & \mathrm{V} & \mathrm{V}_{\mathrm{c}} & \mathrm{V}_{\mathrm{c}} \\
\mathrm{I} & \mid & \mid & \mid & \mid & \mid & \mid & \mid \\
\mathrm{V} & \mathrm{V}_{\mathrm{c}} & \mathrm{V} & \mathrm{V}_{\mathrm{c}} & \mathrm{C} & \mathrm{C} & \mathrm{C} & \mathrm{C}
\end{array}
$$

In the locational gesture, $|\mathrm{C}|$ and $|\mathrm{V}|$ and $\left|\mathrm{C}_{\mathrm{v}}\right|$ and $\left|\mathrm{V}_{\mathrm{c}}\right|$ receive two interpretations; one for governing position and one for dependent position in the primary subgesture, but only one when occurring in the secondary subgesture [van der Hulst divides the locational gesture into a primary and a secondary subgesture, as shown in (3)]. These interpretations are listed in (17) (cf. van der Hulst, 1994, p. 454). Note that $\mathrm{V}_{\mathrm{c}}$ is later banned not only as an individual vowel representation, but also as a possible secondary articulation:



These componential interpretations lead to the following structures for the three basic vowels $/ \mathrm{i} /, / \mathrm{u} /$ and $/ \mathrm{a} /$ :

a.<smiles>CC=[V]C</smiles>

b. high front

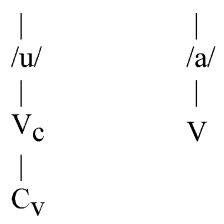

$\underset{\text { round }}{\mid}$

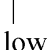


(18a) specifies the componential structures and (18b) the interpretations according to (17) of these vowels. From (18b) it is clear that with $|\mathrm{C}|$ and $|\mathrm{V}|$ as basic components the triangular interpretation of the vowel space has been abandoned. Instead the vowel space is now quadrangular: 'high' versus 'low' and 'front' versus 'round'.

Vowels such as $/ \mathrm{e} /, / \varepsilon /$ and $/ \mathrm{o} /, / 0 /$ are assigned these representations:
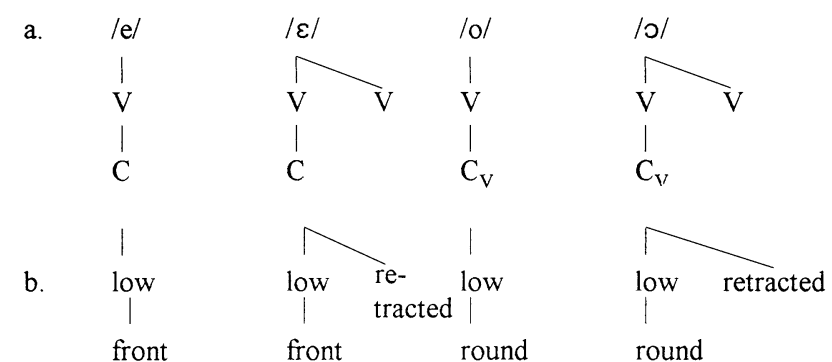

Let us dwell on the representations for $/ \mathbf{i} /$ and $/ \mathrm{w} /$ as well. Recall how in (13) these were only assigned extrinsic features. A representation exclusively in terms of extrinsic features corresponds to a componentless or empty representation within the CV-model. Consequently, CV-phonology stipulates that $/ \mathrm{i} /$ and $/ \mathrm{w} / \mathrm{do}$ not contain a specification in the primary locational subgesture. But apparently a secondary locational representation may or may not be present. It is possible that $/ \mathrm{w} / \mathrm{has}$ such a secondary locational specification, whilst /i/ lacks it. The most radical possibility, viz. complete absence of a locational gesture, is claimed to be the appropriate representation for $/ \mathrm{a} /$. Thus, van der Hulst makes a distinction between empty primary locational subgesture and complete absence of the locational gesture. Presumably, these possibilities can be put to use as follows:

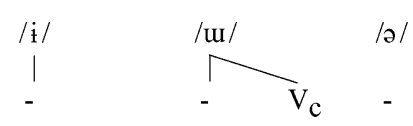

The difference between these three is then firstly one of absence versus presence of a locational gesture $(/ \mathrm{a} /$, on the one hand, and $/ \mathbf{i} /$ and $/ \mathrm{w} /$, on the other) and secondly one of presence versus absence of a secondary subgesture $(/ \mathrm{w} /$ versus $/ \mathbf{i} /)$ (see Section 5.3 for further discussion of the representation for $/ \mathrm{u} /$ ).

Interestingly, the secondary subgesture is used in the representation of a range of vowels. It is not only employed in the representation for $/ \varepsilon /$ and $/ 0 /$ as shown in (19). It is also used to distinguish between $/ \mathrm{i} /$ and $/ \mathrm{I} /$ and $/ \mathrm{u} /$ and $/ \mathrm{v} /$ (cf. van der Hulst, 1995, p. 462):

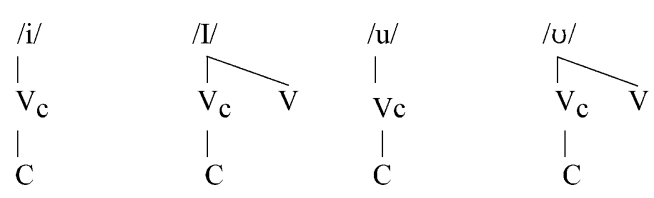


Clearly van der Hulst's CV-framework presents an innovation within the tradition of component-based models by claiming that the two components, $\mathrm{C}$ and $\mathrm{V}$, are adequate for the description of not only the locational gesture but in fact also the categorial gesture (for a description of the categorial gesture, see van der Hulst, 1995). And this claim gains further support when $\mathrm{C}$ and $\mathrm{V}$ can also be shown to constitute the basic elements of suprasegmental structure. But the extensive use of $\mathrm{C}$ and $\mathrm{V}$ also has its drawbacks. This will become obvious below once we consider the applicability of the different representational models. But since we shall return in a moment once more to a triangular componential description of the vowel space, let us conclude this section with a summary of these drawbacks.

Firstly, the introduction of $|\mathrm{C}|$ and $|\mathrm{V}|$ into the locational gesture entails that the vowel space is interpreted as quadrangular rather than triangular. This means that the insight that $/ \mathrm{i} /, / \mathrm{a} /$ and $/ \mathrm{u} /$ are basic vowels is lost. Secondly, it is problematical that the category $\mathrm{V}_{\mathrm{c}}$ is restricted to occur only with a dependent $\mathrm{C}$ or $\mathrm{C}_{\mathrm{v}}$ (cf. van der Hulst, 1995, p. 459). It cannot individually represent a vowel nor a secondary articulation [for the use of $\mathrm{V}_{\mathrm{c}}$ in (20) see again Section 5.3]. This is problematical when $\mathrm{V}_{\mathrm{c}}$ is one of the four basic categories generated by the components $\mathrm{V}$ and $\mathrm{C}$. Thirdly, it is not obvious why the difference between, for example, $/ \varepsilon /$ and $/ \mathfrak{x} /$ and $/ \mathrm{o} /$ and $/ \mathrm{p} /$ should be as shown:
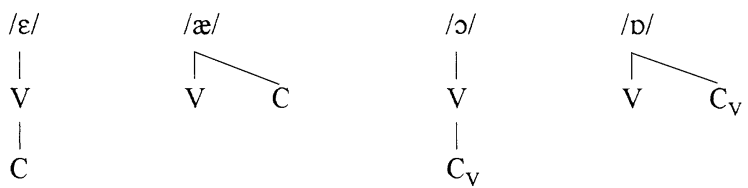

when the difference of vowel height elsewhere [compare with (19) and (21)] is expressed in terms of a secondary V. It also remains to be explained why $/ \mathfrak{x} /$ and $/ \mathfrak{o} /$ in (22) are best described in terms of a primary and a secondary locational gesture rather than in terms of an integrated representation in the primary locational gesture. Fourthly, it is odd that a secondary V, which stands for 'retracted' is appropriate to describe both $/ \mathrm{I} /$ and $/ \mathrm{U} /$, in particular how can this be appropriate for the latter? Fifthly, it is not clear how the difference between an empty and an absent primary locational gesture, as put to use in (20) before, should be interpreted phonetically. The distinction seems to be inherited from the earlier work of van der Hulst [see (13)] and is based on the claim that a representation may lack intrinsic features, as in $/ \mathbf{i} /$ and $/ \mathrm{u} /$, or be completely devoid of both intrinsic and extrinsic features. But how this distinction between intrinsic and extrinsic features or complete absence of features is built into the CV-framework remains unexplained.

\subsection{In defence of the triangular componential analysis of the vowel space}

Although it clearly provides new and intriguing insights, CV phonology evidently fails to provide equally satisfactory solutions to all aspects of the vowel description. Therefore we return in this section once more to a consideration of how the vowel 
space may be described when the basic units are unary dependency components and when the basic structure they form is triangular.

As in classical dependency phonology, it is our hypothesis that $|\mathrm{a}|$ is the basic unary component. This basic property appears from the facts that either $|\mathrm{a}|$ occurs alone or it always forms a constituent part of other components. As part of another component, $|\mathrm{a}|$ is negated and either $|\mathbf{i}|$-coloured or $|\mathrm{u}|$-coloured (indicated by superscripts henceforth), i.e. $\left|\sim \mathrm{a}^{\mathrm{i}}\right|$ and $\left|\sim \mathrm{a}^{\mathrm{u}}\right|$. It is our contention that we need no other components than $|\mathrm{a}|,\left|\sim \mathrm{a}^{\mathrm{i}}\right|$ and $\left|\sim \mathrm{a}^{\mathrm{u}}\right|$. We define these possibilities as follows ('maximally' means here what is maximally possible for a vocalic articulation):

(23) a

$\sim \mathrm{a} \quad$ closed tongue body constriction

$\sim \mathrm{a}^{\mathrm{i}} \quad$ maximally closed palatal constriction, rounding marked

$\sim \mathrm{a}^{\mathrm{u}} \quad$ maximally closed velar constriction, rounding unmarked

As in CV phonology, it is our claim that the fourth component $|\partial|$ is redundant. We need then another instrument to characterise central and back unrounded vowels. The possibility of leaving the locational gesture empty as in CV phonology is one possible substitute for $|a|$. Another is to make use of the representation $|\sim a|$. Finally, we contend that unmarked properties can be added to other componential representations. This accounts for the possibility of adding $\left|\sim \mathrm{a}^{\mathrm{u}}\right|$ to specify rounding in for example front vowels.

Henceforth we use the representation simple $|\mathrm{i}|$ to denote what really is $\left|\sim \mathrm{a}^{\mathrm{i}}\right|$ and simple $|\mathrm{u}|$ stand for $\left|\sim \mathrm{a}^{\mathrm{u}}\right|$. Given the definitions in (23), it is now possible to express $/ \mathrm{i} /, / \mathrm{u} /$ and $/ \mathrm{a} /$ individually in terms of $|\mathrm{i}|,|\mathrm{u}|$ and $|\mathrm{a}|$, without this being inappropriate for $/ \mathrm{i} /$ and $/ \mathrm{u} /$ (cf. the discussion in Section 3.3). The definitions also allow us to express (unrounded) front vowels as combinations of $|\mathbf{i}|$ and $|\mathrm{a}|$, and (rounded) back vowels as combinations of $|\mathbf{u}|$ and $|\mathrm{a}|$. As in classical dependency phonology, these combinations will typically be expressed in terms of dependency relations, as shown in (7). Relative dominance/dependence of the components in these combinations ensures the appropriate 'mellowing' of the peripheral values which characterise the non-peripheral vowel qualities in the vowel space.

The contention that an empty articulatory gesture is an appropriate representation for $/ \partial /$ entails that there is no need for the component $|\partial|$ to describe the vowel qualities in the centre of the vowel space. Using an empty articulatory gesture instead of $|a|$ to denote $/ \partial /$ is motivated by the following properties of $/ \partial /$ : (i) it is a non-distinct, neutral vowel produced with the tongue and the lips in their rest position, (ii) it is the product of reduction when vowels are weakened in unstressed syllables, (iii) in a general weakening process it is the last stage before complete loss of a vowel. It is important to note that although relative complexity typically has been directly reflected in the dependency representations such that least complex entails fewest components, absence of a representation in the case of /o/ does not necessarily make it the least complex vowel type. Establishing the relative complexity of two sounds requires that the environment in which this is established is the same for the sounds in question, and as a rule /o/, unlike other vowels, fails to occur in stressed 
syllables. The basis for complexity calculations should then not be identical for $/ \mathrm{o} /$ and other vowels.

The component $|a|$ has played a central role in the characterisation of a range of other central and unrounded vowels in classical dependency phonology (Anderson and Ewen, 1987, Chapter 6). Its abolition in CV phonology led to a new interpretation of these central and unrounded vowels. In particular, as is apparent from (20), it entailed that it is possible for the locational gesture not only to be empty but also to be completely absent. We are not prepared to go quite as far as CV phonology and adopt these two empty representations. As pointed out earlier, we are not sure how these two empty specifications differ. Nor do we intend to adopt the idea presented in (10) that it is natural for a component to occur twice in a representation-both as governor and as dependent-unless two such components co-occur with another component. The drawback of the representation in (10), involving two identical components alone, is that it leads to more complex representations for less complex vowels and questions the 'atomic' status of the components.

Instead, in order to account for unrounded back vowels, we wish to make use of the property of (23) that nonlow vowels can be nonlow in three ways: i-coloured, $\mathrm{u}$-coloured and simple $|\sim \mathrm{a}|$. High central vowels like $/ \mathbf{i} / \mathrm{and} / \mathfrak{u} /$ will then involve $|\sim \mathrm{a}|$, as will half-close and half-open central vowels like $/ \Im /$ and $/ \Theta /$ and $/ 3 / \mathrm{hd} / \boldsymbol{\theta} /$. As very few languages have vowels which differ just by being front central and back with all other features remaining the same, $|\sim \mathrm{a}|$ alone will usually suffice as a representation for a central vowel. But we shall also use $|\sim \mathrm{a}|$ for other high vowels, in particular unrounded back vowels. This means that a rare case like Papuan Nimboran (cf. Maddieson, 1984, p. 357), in which /i/, /i / and / w/ are the only contrasting high vowels, will pose a problem. How should the latter two be distinguished if both involve $|\sim \mathrm{a}|$ ?

Anderson and Ewen (1987, Chapter 6) postulate that their component $|\partial|$, centrality, is relevant for the description of, among others, back unrounded vowels. In particular, they posit the representation $|\mathrm{i}, \mathrm{u}, \mathrm{\partial}|$ for the high unrounded $/ \mathrm{u} /$. The motivation for the three components in this representation is roughly the following: $|\mathbf{u}|$ is present because $/ \mathrm{u} /$ is a back vowel, $|\mathbf{i}|$ is present to specify unrounding, and $|\mathbf{a}|$ is present partly because $|\mathbf{i}|$ would be insufficient alone $(|i, u|$ specifies [ü]) and partly because acoustic and perceptual properties indicate that back unrounded vowels are between front unrounded and back rounded vowels, and $\mid$ a $\mid$ signifies centrality. But there seems to be no need for the component $|\mathrm{i}|$ in the representation $|\mathrm{i}, \mathrm{u}, \mathrm{\partial}|$. If its presence is to insure no rounding, then this is guaranteed by the presence of $|\sim \mathrm{a}|$. The crucial point is whether we need $|\mathrm{u}|$. It does not seem to be the case if $/ \mathrm{u} / \mathrm{does}$ not contrast with high central vowels. But when it does, as in Nimboran which also has $/ \dot{i} /$, then it should combine with $|\mathrm{u}|$ to express velar constriction. In this case the presence of $|\sim \mathrm{a}|$ insures no rounding, i.e. the Nimboran contrast should be represented as shown in (24):

$$
\begin{array}{ll}
/ \mathrm{i} / & / \mathrm{w} / \\
|\sim \mathrm{a}| & |\sim \mathrm{a}, \mathrm{u}|
\end{array}
$$


If we compare (24) and the representation of / $/ \mathrm{a}$ in terms of an empty articulatory gesture with the representations given in (20), which again are indebted to (13), then it is clear that $|\sim \mathrm{a}|$ in the present modified version corresponds to an empty primary articulatory gesture in CV phonology and an empty specification in the present modified framework corresponds to the complete absence of the articulatory gesture in CV phonology. To us this is a good sign that the triangular interpretation of dependency phonology, which assumes the basic status of $|\mathbf{a}|$, is as good an instrument as the quadrangular interpretation of CV phonology to describe the vowel space. In addition, the triangular interpretation suggested here has the advantage that it does not have to posit and interpret two types of empty representation.

\section{The two types of hierarchy compared}

Given this brief outline of (the relevant parts of) both feature geometry and dependency phonology, it is now time that we examine in detail the applicability of these two types of representational model. Our comparison will, on the one hand, focus on stricture-based feature geometry - and less so on articulator-based feature geometry for the reasons outlined earlier - and, on the other, on CV phonology and the original version of dependency phonology with the modifications presented earlier in Section 3.4 and in Staun (1996). What we shall refer to henceforth as dependency phonology will then deviate somewhat from the classical version of dependency phonology (Anderson and Ewen, 1987). Moreover, unlike the way we have used it up until now, where it has been used to refer to any model employing monovalent components which may interact in dependency relationships, the term dependency phonology will only refer to this particular variety of the dependency-based phonological models, i.e. the variety which has maintained a range of monovalent components and not reduced these to just two, viz. $|\mathrm{C}|$ and $|\mathrm{V}|$, which allows these components to interact in dependency relationships and which assumes a triangular interpretation of the vowel space. That is, from now on dependency phonology and $\mathrm{CV}$ phonology will be regarded as two separate but very similar models. We test the power of these two models and articulator-based and stricture-based feature geometry against two types of evidence: evidence which relates to vowel height, and evidence which relates to location, the latter evidence in particular as it is manifested in secondary articulation and vowel harmony.

\subsection{Vowel height}

In Section 3.2 it was pointed out that an objection raised against the classical dependency description of vowels which employs $|\mathrm{i}|,|\mathrm{u}|$ and $|\mathrm{a}|$ (cf. Anderson and Ewen, 1987) is that it cannot express the class of [+high] or [-low] vowels. As a consequence, both Clements and Hume and Kaze argue that it is a problem for this type of model to account for a vowel closing process such as that found in some dialects of Italian, which shifts a tonic vowel up one step as shown in (25) (cf. Clements and Hume, 1995; Kaze, 1991): 
(25)

$$
\begin{aligned}
& \text { é } \rightarrow \dot{1} \\
& \text { óń } \\
& \varepsilon \rightarrow e ́ \\
& o \rightarrow o ́
\end{aligned}
$$

The problem, Kaze argues (op. cit), is that in such a component-based model the spreading of a posttonic $/ \mathrm{u} /$ in, for example, $/ \mathrm{kwer}-\mathrm{u} /$ will result in a front rounded tonic vowel, i.e. in the non-occurring form $* / \mathrm{kwöru} /$, because the component which spreads does not correspond to a feature [high], but will be the component $|\mathrm{u}|$.

The same criticism led van der Hulst to introduce the hierarchical organisation shown in (8). By introducing this, van der Hulst adopts a quadrangular view of the vowel space, a view which dominates his work thereafter as described in Section 3.3. But a closer inspection reveals that it is unnecessary to introduce a hierarchy such as that given in (8), provided we ensure that the definition of the three fundamental components is such that (i) when the three components $|\mathbf{i}|,|\mathbf{u}|$ and $|\mathrm{a}|$ occur alone they specify the three most basic vowels $/ \mathrm{i} /, / \mathrm{u} /$ and $/ \mathrm{a} /$, respectively, and (ii) when it occurs in combination with other components, $|\mathrm{u}|$ designates velar constriction and rounding, $|\mathrm{i}|$ palatal constriction and advanced tongue root and $|\mathrm{a}|$ openness and pharyngeal constriction. These properties are exactly those specified in the extended version outlined in Section 3.4.

But how do we solve the alleged problem of not generating $* /$ kwöru/? Vowel raising processes have been dealt with before in dependency phonology. In each such account the notion of a negated component, in particular negated $|\mathrm{a}|$ has played a central part. In such accounts, as in the proposal summarised in (23), the properties contained in $|\sim \mathrm{a}|$ is closed tongue body constriction [no openness and no pharyngeal constriction in earlier descriptions (see e.g. Anderson, 1980; Staun, 1983)]. In other words, in the hierarchy displayed in (8), $|\sim \mathrm{a}|$ subsumes the properties which c-depends on the a-tier node. The possibility of using a negated $|\mathrm{a}|$-component follows from the fact that this component enters equally naturally into i-dependency relationships with the $|\mathrm{i}|$-component and the $|\mathrm{u}|$-component, whilst the latter two do not combine with each other in i-dependency relationships. Thus, despite the claims of both Clements and Hume and Kaze, a unique specification of high vowels is perfectly possible within the dependency-based model, viz. as $|\sim \mathrm{a}|$.

Such a class-specification allows us to account for the Italian data given in (25). Take, for example, the raising of the two close mid vowels /e/ (as in / kweru/) and /o/. We can represent this raising as shown in (26):

(a)

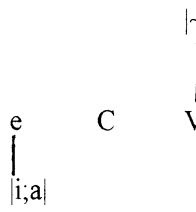

(c)

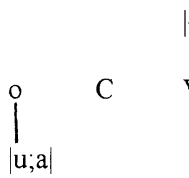

(b)

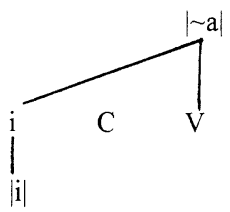

(d)

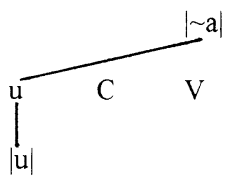


The change of $|\mathbf{i} ; \mathrm{a}| \rightarrow|\mathrm{i}|$ and $|\mathrm{u} ; \mathrm{a}| \rightarrow|\mathrm{u}|$ follows directly from the fact that when $|\mathrm{i} ; \mathrm{a}|$ and $|\mathrm{u} ; \mathrm{a}|$ have added $|\sim \mathrm{a}|$ to them, as happens when the quality of the following vowel spreads, the result is that they become more $|\sim \mathrm{a}|$. For $/ \mathrm{e} /$ and $/ \mathrm{o} /$ this means that they will lose whatever $|\mathbf{a}|$-ness they contain, as $|\mathrm{a}|$-ness is already in subordinate or dependent position in these two vowels. The next step is absence of $|\mathrm{a}|$, as is apparent from (5), and consequently only the preponderant $|\mathrm{i}|$ and $|\mathrm{u}|$ remain after the spreading and these specify $/ \mathrm{i} /$ and $/ \mathrm{u} /$, respectively.

Kaze's feature-based description also accounts well for the spreading when the tonic is a close mid vowel, i.e. / / / and /o/. But the feature account faces a problem when the tonic is a low mid vowel, i.e. a vowel specified as $[-$ high $],[+/-$ back $],[+/-$ round $]$ and $[+$ low], i.e. $/ \varepsilon /$ or $/ \mathrm{o} /$. The problem is that when the feature $[+$ high] spreads to such a vowel the result is a vowel which is simultaneously [+low] and [+ high], which is an impossible specification given the definition of these two features. As observed by Kaze, two attempts have been made to solve this problem (cf. Calabrese, 1987). One is to separate the conflicting features and associate them with two different elements of the CV tier. This is appropriate for one type of dialect. The other, which is appropriate for another type of dialect, is to have a rule which negates the conflicting features so $[+$ high $]$ becomes $[-$ high $]$ and $[+$ low $]$ becomes $[-$ low $]$, a negation which will result in the desired specification, /e/ and /o/ being both [-high] and [-low]. The dependency-based model, however, does not have to resort to such extra and slightly spurious repair rules. When the spreading of the posttonic vowel is formulated in terms of $|\sim a|$, this will account directly for high mid and low mid vowels alike.

But will CV phonology be able to account for the vowel raising process? The environment causing the raising can be uniquely specified as a vowel which has a dominant $\mathrm{V}_{\mathrm{c}}$, /i/ being specified as $\mathrm{V}_{\mathrm{c}} \rightarrow \mathrm{C}$ and $/ \mathrm{u} /$ as $\mathrm{V}_{\mathrm{c}} \rightarrow \mathrm{C}_{\mathrm{v}}$. The actual process may then be expressed as follows:

(a)

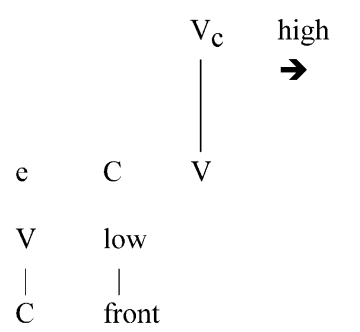

(c)



(b)

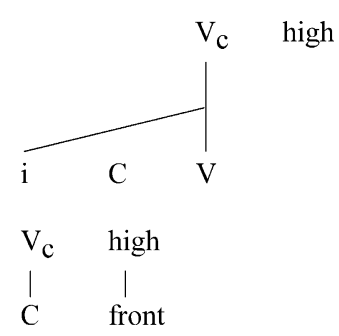

(d)

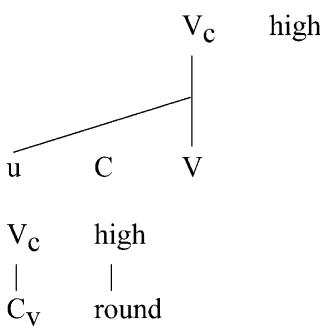


For this to be a plausible account of the raising phenomena, it is essential that the spreading of the specification governing $\mathrm{V}_{\mathrm{c}}$ (high) actually has the desired effect. But is the 'logic' of the CV representations actually such that when governing $\mathrm{V}_{\mathrm{c}}$ spreads then the representations become restructured in the desired way? In an attempt to answer this question, consider, for example, the following representations for $/ \mathrm{i}, \mathrm{e}, \varepsilon /$ :



In fact, a situation like that encountered by Kaze, discussed earlier, is the result when $\mathrm{V}_{\mathrm{c}}$ spreads. Both $/ \mathrm{e} /$ and $/ \varepsilon /$ will after the spreading be specified as low and high at the same time. This is perhaps less problematical when the primitives are unary components, rather than features, and enter into dependency relationships, but it is not clear how the representation for $/ \varepsilon /$ is restructured to the representation for $/ \mathrm{e} /$ because high is added. Why should the spreading of high lead to the loss of the secondary locational representation retracted and then leave no trace otherwise? Similarly, a 'logic' must be established to account for the fact that when high spreads and the tonic vowel is $\mathrm{V}$ governing $\mathrm{C}$, i.e. low governing front as in the representation for $/ \varepsilon /$, this spreading leads to a vowel which has high governing front. Somehow this must involve the replacement of low by high, but why it should have this effect is not clear. If, on the other hand, the gradual relation between vowels such as those in (28) appear directly, as in the representations of dependency phonology in terms of the preponderance of one or the other component, then the spreading of high will receive an obvious interpretation: either as an increase or as a decrease of the preponderant component.

The absence of a clearly scalar continuum of vowel height is then a weakness of $\mathrm{CV}$ phonology. It is also a problem that the spreading of high can be argued to lead to vowels being specified as both high and low simultaneously. In this respect $\mathrm{CV}$ phonology faces the same problem as Kaze's feature-based account.

But this situation does not hold for all feature-based models. Clements' stricturebased feature geometry, does not encounter such problems. In this framework the change of the tonic vowel can be formulated as the spreading of a minus value for the feature [open 1 , as shown in (29). Consequently, it is not necessary to introduce repair rules like those used by Calabrese (1987).

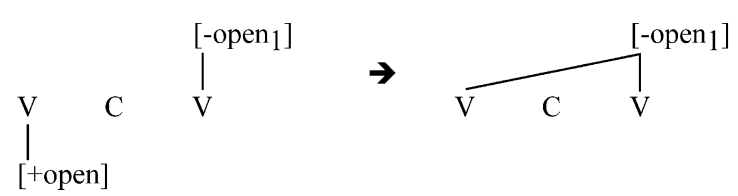


Stricture-based feature geometry and dependency phonology can then capture changes of vowel height well. We have not looked at the descriptive potential of the articulator-based version of feature geometry. This is because, as noted earlier in Section 3.1, the articulator-based model suffers from at least two deficiencies. Firstly, it is a problem of the articulator-based model that [ATR] (the feature used to allow for more than three vowel heights) does not hang from the place node, but is a dependent of the supralaryngeal node. When it is not associated with place it cannot act together with the other vowel features. As such it is unable to partake in the phonological rules and constraints which affect the place hierarchy. And secondly, the articulator-based model does not hypothesise that vowel height functions independently; instead it claims that it functions together with dorsal features. But the Italian data considered here clearly demonstrate that vowel height does not behave in this way.

The independent status of vowel height in both stricture-based feature geometry and dependency phonology is then the property which enables us capture the Italian vowel raising phenomena directly. So long as independent nodes or components corresponding to 'aperture' or 'lowness' [cf. (5a) and (6)] fail to be part of the stricture-based feature geometry and $\mathrm{CV}$ phonology, these descriptive models will provide less optimal accounts of such raising phenomena.

\subsection{Vocalic place}

\subsubsection{A brief review}

We turn now to the other important aspect of vowel description: how to account for locational properties of vowels such as front, central and back and evidence relating to these. Since consonantal place is usually described either by using the same or very similar features as describe front, central and back vowels, our account will also deal with the structure of consonantal place and the interrelation between consonantal place and vocalic place in so far as this is relevant for the discussion. We test the descriptive power of the two types of model against two types of phenomena which relate to place: secondary articulation and vowel harmony.

Let us first briefly review the proposals of the two versions of feature geometry. As noted earlier, the two models make different predictions as regards vocalic place. This is apparent from the feature trees in (4) and (5). The articulator-based model [outlined in (4)] assigns all vowel features to the dorsal node. Consequently, this model predicts that vowels only structure with dorsal but not with coronal consonants. The stricture-based model, on the other hand, whose major innovation is the introduction of a V-place node and a C-place node, and the introduction of both a coronal and a dorsal branch under these place nodes, makes the prediction that front vowels are coronal and structure with coronal consonants and back vowels are dorsal and structure with dorsal consonants. To support the stricture-based model, Clements lists evidence from secondary articulation and vowel harmony. This is the reason that we shall focus on this evidence presently.

Dependency phonology characterises front vowels as those which contain $|\mathrm{i}|$ and back vowels as those which have $|\sim \mathrm{i}|$. Central vowels essentially involve the fourth 
component $|\partial|$ in the original proposal (cf. Anderson and Ewen, 1987) and $|\sim \mathrm{a}|$ in the modified version proposed in Section 3.4. How vocalic place interrelates with consonantal place in this model depends on the type of C-place description chosen. In one version (cf. Staun, 1996), which we shall follow here, the consonantal place node heads a node which is a multiple place node. This multiple place node again has a node hanging from it, specifying dorsal and non-dorsal articulations in so far as such specifications are needed phonologically. The multiple place node is termed the L-P node because it can assume any of the place values from labial (L) to pharyngeal $(\mathrm{Ph})$ (dental and alveolar constitute one value, however, see Staun op.cit. for discussion). Thus, the overall locational tree for a consonant looks as shown in (30):

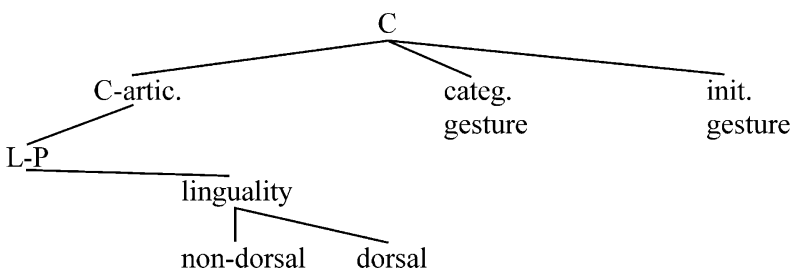

A set of association links connect the individual values of the L-P node with the vowel components to establish the articulatory correlates of vowels and consonants. The association links are not included in (30). Instead we list them in (31):

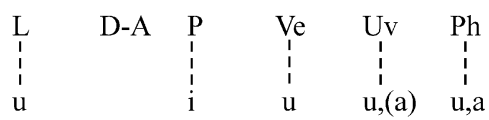

in which $\mathrm{L}=$ labial, $\mathrm{D}-\mathrm{A}=$ dentoalveolar, $\mathrm{P}=$ palatal, $\mathrm{Ve}=$ velar, $\mathrm{Uv}=$ uvular, $\mathrm{Ph}=$ pharyngeal. It may seem problematical that $|\mathrm{u}|$ is both associated with $\mathrm{L}$ and $\mathrm{Ve}$, but this is due to the fact that $|\mathbf{u}|$ is defined as both velar constriction and rounding. Thus when linked with $\mathrm{L}$ it is the roundness property which dominates, whilst it is velar constriction which is predominant in other associations. For further discussion see Staun (1996).

$\mathrm{CV}$ phonology, the other component-based description, specifies front vowels as complex V-headed segments which have a dependent $\mathrm{C}$, either in the primary or in the secondary locational gesture, and back vowels as those complex segments which are $\mathrm{V}$-headed and have a dependent $\mathrm{C}_{\mathrm{v}}$ either in the primary or in the secondary locational gesture. Central vowels are specified in terms of an empty locational gesture as shown in (20). Similar specifications are used for consonants, except that these are not $\mathrm{V}$-headed but $\mathrm{C}$-headed. In complex $\mathrm{C}$-headed representations a dominant $\mathrm{C}$ is interpreted as coronal and a dominant $\mathrm{C}_{\mathrm{v}}$ as labial, whilst the empty locational gesture is interpreted as dorsal. We summarise the vowel and consonant representations in (32) ( $\mathrm{V}$ in front vowels can also be $\mathrm{V}_{\mathrm{c}}$ ): 


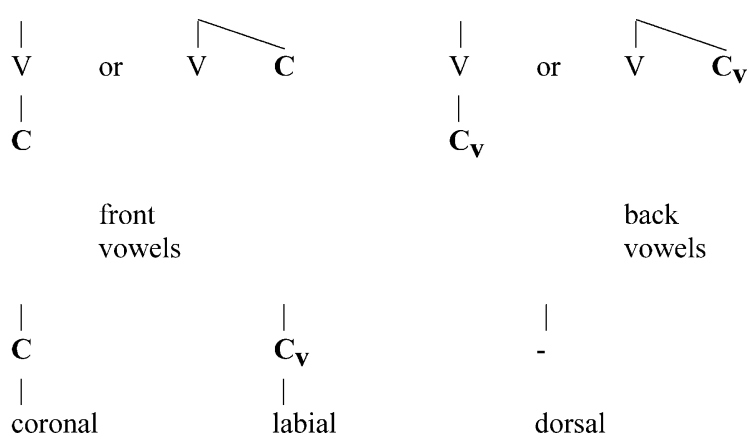

The crucial structural properties have been represented in bold face. For front vowels and coronals the shared property is $\mathrm{C}$ either as dependent or governor. For back vowels and dorsal consonants there is no shared property. Instead back vowels share the property $\mathrm{C}_{\mathrm{v}}$ with labial consonants. At first sight the structural similarity between vowels and consonants is then much less obvious in CV phonology than in the stricture-based feature geometry and than in the version of dependency phonology considered here. But let us not pass any further judgement, before we have looked at the way $\mathrm{CV}$ phonology can handle some concrete data.

We begin by looking at the data concerning secondary articulation. In particular, we shall consider (i) how secondary articulation in general is allowed for in the two types of representational framework and how the individual models are able to account for in particular palatalisations, and (ii) whether the way the individual models specify secondary articulation may be used to block otherwise regular phonological processes from applying, i.e. how they may be used to express what is often referred to as barriers.

\subsubsection{Secondary articulation I}

Let us first attempt to establish how secondary articulation is captured within stricture-based feature geometry. In this version of feature geometry, secondary articulation is expressed by subjoining a V-place specification with its s-dependents to a C-place specification. Thus palatalisation and velarisation, for example, appear as shown in (33), which shows palatalised and velarised [t]:
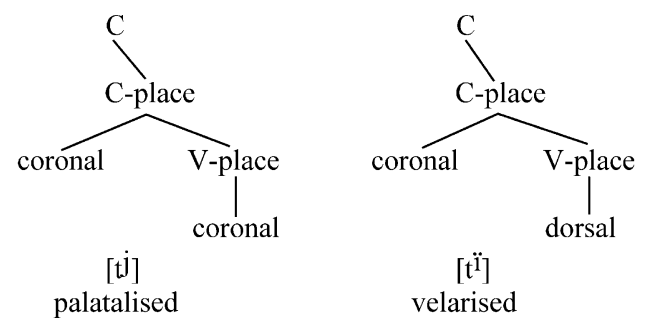
Apparently, such a description has a number of advantages over one formulated within the articulator-based feature geometry, which describes secondary articulation - as does SPE-based models - in terms of a plus specification for one or more of the dorsal features [high], [low] and [back] added to a non-tongue-body consonant. The first advantage is that the stricture-based framework is able to express the difference between plain $[\mathrm{p}]$ and labialised $\left[\mathrm{p}^{\mathrm{w}}\right]$ without having to introduce the feature [round], because labial is interpreted differently depending on whether it s-depends on C-place or V-place:



The second advantage is that this kind of representation expresses directly those instances where the labialisation becomes the dominant feature, as when Indo-European $\left[* \mathrm{k}^{\mathrm{w}}\right]$ appears in Greek as [p]. This change simply involves a promotion of the V-place [labial], so it is the only feature which s-depends on the higher C-place node.

A third advantage of the stricture-oriented model is its ability to express the palatalisation of a velar consonant induced by an adjacent front vowel, or the further change of the palatalised consonant to a full palatal sound (cf. Hume, 1992). Since front vowels in the stricture-oriented framework are coronal, palatalisition will be expressed as the spreading of a V-place coronal. If the palatalised velar is further changed to a full palatal, then the V-place coronal takes over the role of the dorsal node which s-depended on the C-place node. We display these two changes in (35), where (a) shows palatalisation and (b) the change of the palatalised sound to a fully palatal sound:

a.


b.

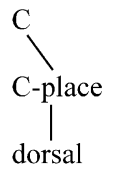

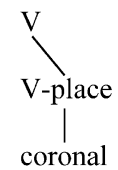
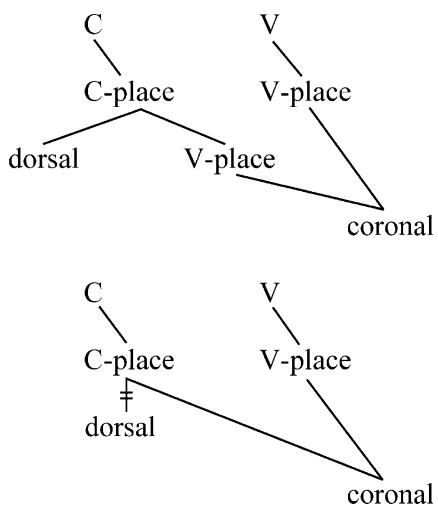
The advantage of this account is that it can capture both processes in terms of coronality, in particular in terms of the relative structural dominance of this property. The articulator-based model (and other SPE-oriented models), by contrast, would have to express the process in (35a) as a change of $[+$ back] to [-back] and that in (35b) as a change from dorsal to coronal, with the additional problem of having to explain why the target is coronal and not labial for example. Thus the articulatorbased model cannot capture the two changes in the same uniform way as the stricturebased model.

But can CV phonology and dependency phonology capture these palatalisations in a uniform way? We consider first CV phonology. From (36) it is apparent how the components $\mathrm{C}$ and $\mathrm{V}$ are interpreted as secondary articulations. Their interpretation varies depending on whether the primary articulation is $\mathrm{C}$-headed or V-headed (recall that $\mathrm{V}_{\mathrm{C}}$ is banned as a secondary articulation, cf. van der Hulst, 1994, p. 459):

$\begin{array}{lll} & \text { C-headed } & \text { V-headed } \\ \mathrm{C} & \text { palatalised } & \text { front } \\ \mathrm{V} & \text { pharyngealised } & \begin{array}{l}\text { retracted } \\ \text { round }\end{array}\end{array}$

It is a conspicuous feature of (36) that velarisation is not a possible secondary articulation. This follows from the fact that velarisation is captured in terms of the representation for dorsality. In CV phonology dorsality is expressed in terms of an empty primary gesture, but according to van der Hulst (1994, p. 460) dependent structures, including the secondary locational gesture, may not be empty. As a consequence, it is impossible to express the velarised [t] ([t]]) shown in (33). Palatalised [t], i.e. $\left[\mathrm{t}^{\mathrm{j}}\right]$, on the other hand, as well as labialised $[\mathrm{p}]\left(\left[\mathrm{p}^{\mathrm{w}}\right]\right)$ are not difficult to allow for. These secondary properties are available within CV phonology. (37) lists the consonant types given in (33) and (34), as they would appear in CV phonology:

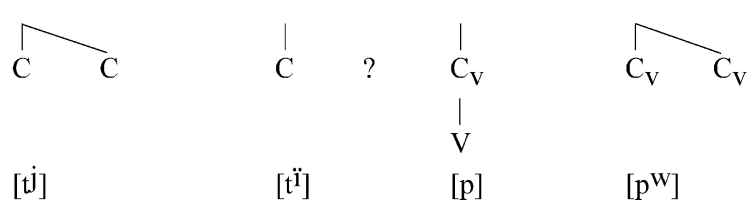

The question mark indicates that it is not clear how velarisation should be expressed. But is CV phonology able to account for the palatalisation processes outlined in (35)? The palatalisation of a velar can be expressed as shown in (38a) and the transformation to a fully palatal consonant as shown in (38b): 




but does (38b) actually express the transformation of a palatalised consonant to a fully palatal consonant? The claim of (38b) is that the $\mathrm{i}$-dependent $\mathrm{C}$ is aligned to the empty representation of the preceding consonant. But as is apparent from (38a) this is also how palatalisation is expressed, as appears from (37) too. Becoming a full palatal should then involve something extra. Obviously, this extra property should be that the empty representation is replaced by the dependent $\mathrm{C}$ from the following vowel. This way we obtain a representation comparable with the feature geometrical one given in (35b) in which the dorsal node is disconnected with the C-place node and the coronal node is the only node which s-depends on the C-place node. However, is this at all the way a palatal consonant is represented in CV phonology? In fact, the answer is no. A single $\mathrm{C}$ in the primary locational gesture denotes a nonlaminal, non-postalveolar apical denti-alveolar consonant (cf. van der Hulst, 1995, p. 465). Then it cannot also be the appropriate representation for a palatal consonant. It seems that the only possible representation for palatals is $\mathrm{C}$ in the primary locational gesture and $\mathrm{C}$ in the secondary locational gesture, i.e. what, if the interpretations in (36) are followed, may be characterised as a palatalised coronal. The problem with this solution is that it just does not enable us to make a distinction between a palatal and palatalised coronal.

Can dependency phonology then capture these palatalisation phenomena in a way which avoids the problems encountered by $\mathrm{CV}$ phonology and which is as uniform as the feature geometrical account outlined in (35)? In order to answer this question, it is necessary first to establish how consonantal place is accounted for within the tradition of this framework. One such account has been suggested quite recently by Staun (1996). This work also builds on the assumption that the phonological segment is divided into gestures or hierarchies and that one of these gestures comprises locational properties. Figure (30) shows the structure of this locational hierarchy. One node, the L-P node, specifies the individual places of articulation. These nodes also enter into association links with the vowel components. In this way the articulatory correlates of vowels and consonants are expressed. (31) Shows how the two sets of components link up.

With such properties available to us, we can express both the difference between [p] and $\left[\mathrm{p}^{\mathrm{w}}\right]$ and the processes involving palatalisation represented in (35). As has been pointed out by Staun (1996), secondary articulation within this framework involves the subjunction of the vowel components to the primary consonantal representation (cf. 
also Anderson and Ewen, 1987). Thus the difference between [p] and [ $\left.\mathrm{p}^{\mathrm{w}}\right]$ will appear as in (39), in which L is the labial value assumed by the L-P node:

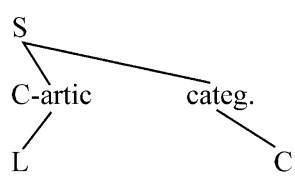

$[\mathrm{p}]$



$\left[\mathrm{p}^{\mathrm{W}}\right]$

In other words, as in the stricture-oriented version of feature geometry, the secondary articulation is specified in terms of an extra branch i-depending on the consonant's articulatory gesture, in particular $\mathrm{V}$-artic $\rightarrow|\mathrm{u}|$ in the case of labialisation. It should be noted that this structure i-depends directly on the node specifying the articulatory gesture. This property indicates that it affects the entire gesture and that $|\mathrm{u}|$ does not enter into a dependency relation with $\mathrm{L}$.

Similarly, palatalisation of $[\mathrm{k}]$ to $\left[\mathrm{k}^{\mathrm{j}}\right]$ caused by a front vowel can be expressed as the subjunction of a $|\mathbf{i}|$-specification, the component $|\mathbf{i}|$ being a property which is shared by all front vowels:

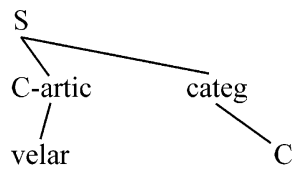

$[\mathrm{k}]$

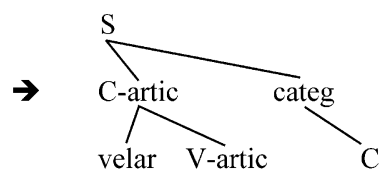

$|\mathrm{i}|$

$[\mathrm{kj}]$

and if necessary the $|\mathrm{i}|$ component can be associated at the same time [as in (35a)] with the consonant and the vowel which causes the change. In those instances where the $\left[\mathrm{k}^{\mathrm{j}}\right]$ changes further and becomes palatal [c], which in feature geometry is expressed as in (35b), these instances can be allowed for by delinking the velar node and promoting the $\mathrm{V}$-artic $\rightarrow|\mathrm{i}|$ specification to primary articulatory status. That this promotion results in a palatal consonant follows from two facts: (i) the association links which exist between the L-P values and the vowel components, and (ii) that a locational $\mathrm{C}$ representation cannot consist of (secondary) vowel components alone (for further discussion see Staun, 1996). As is apparent from (31), $|\mathrm{u}|$ is associated with labial consonants and $|\mathrm{i}|$ with palatal consonants. Thus if a palatalised consonant has its L-P node delinked, the secondary V-artic specification will fill the L-P node and because of the established association links this will result in a palatal. Thus, just like in $\mathrm{CV}$ phonology, the phonetic interpretation of the vowel components in dependency phonology varies depending on whether a segment is a consonant or a vowel.

The same principle can also explain, as in feature geometry, why Indo-European $\left[* \mathrm{k}^{\mathrm{w}}\right]$ appears in Greek as $[\mathrm{p}]$. In a dependency-based representation $\left[* \mathrm{k}^{\mathrm{w}}\right]$ has a 
$\mathrm{V}$-artic $\rightarrow|\mathrm{u}|$ subjoined to its $\mathrm{C}$-artic node. Its emergence in Greek as a bilabial consonant is then a result of the promotion of the secondary articulation which, if headed by a C-artic, gets interpreted as [p]. This interpretation is predicted by the association links in (31) and by the contention that a consonant cannot consist solely of a vowel component. That it surfaces as a labial follows again from the predominant property $|\mathrm{u}|$ has when associated with a labial consonant.

Both the stricture-based version of feature geometry and the component-based dependency model thus offer good accounts of secondary articulations such as those considered here, and indeed account better for them than the articulator-based model of feature geometry and the component-based CV phonology. Observe in this connection, that it is difficult to see how the latter would account for the emergence of Indo-European $\left[* \mathrm{k}^{\mathrm{w}}\right]$ as $[\mathrm{p}]$ in Greek. This development would have to involve the promotion of the secondary specification $\mathrm{C}_{\mathrm{v}}$ (labialised) to the role of filling the primary locational gesture. But the problem is that $\mathrm{C}_{\mathrm{v}}$ alone is not assigned any phonetic interpretation as a primary representation, let alone the representation of a plain labial.

Before we close the discussion of secondary specifications, we shall consider one more type of evidence which will shed light on the descriptive capacities of the representational models examined here. As anticipated earlier, this evidence again concerns V-place subjunction, i.e. secondary specifications, in particular the way such specifications may function as barriers.

\subsubsection{Secondary articulation II: barriers}

The relevant evidence comes from Korean (cf. Hume, 1990). In the Korean dialect dealt with by Hume an umlaut rule applies, according to which a following [i] fronts central and back vowels. The rule applies across noncoronal as well as coronal consonants, but is barred by an intervening palatal [c]. (41) Displays the data:

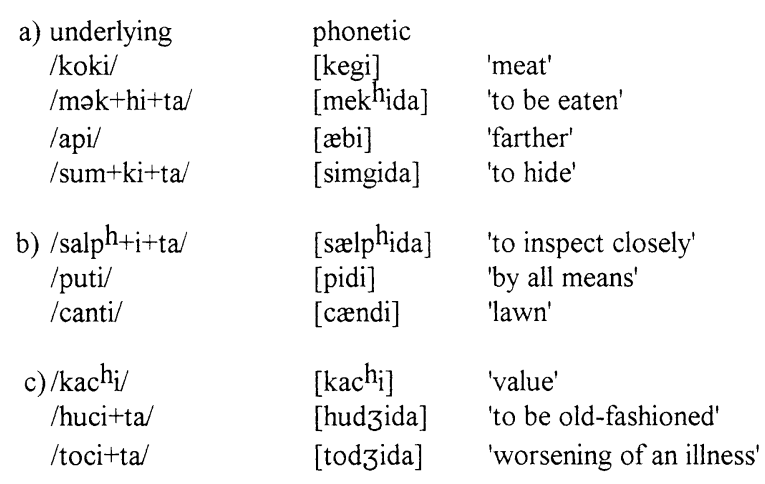

The absence of umlaut in (41c) is explained by Hume as being due to the fact that the palatal consonants systematically have a V-place coronal. The presence of this prevents the V-place feature of the following vowel to spread to the vowel in the preceding syllable, as such a spreading recurrently fails to happen if an intervening consonant is 
specified for the feature which spreads. And in (41c) the palatal consonants are specified for this feature, i.e. according to Hume they are $\mathrm{C} \rightarrow \mathrm{C}-\mathrm{pl} \rightarrow \mathrm{V}-\mathrm{pl} \rightarrow$ [coronal], that is, they are encoded with the relevant feature as a secondary V-pl node.

Thus stricture-based feature geometry is able to express the absence of this umlaut in an immediately obvious way, thanks to the shared property $\rightarrow \mathrm{V}$-pl $\rightarrow$ [coronal]. However, it is not quite clear whether a similar solution is available within $\mathrm{CV}$ phonology. The problem is how the intervening consonants in (41c) should be represented. All the phonological representations suggest that these consonants are palatals, whilst the phonetic representations differ: one is palatal and the other two are what is usually referred to as palato-alveolar. If it is maintained that both types represent palatalised consonants, then they share the secondary locational representation dependent $\mathrm{C}$ [cf. (36)]. As such, the intervening consonants would block the umlaut since the umlaut-causing vowel, a front vowel, is also specified in terms of a dependent $\mathrm{C}$ [cf. (32)]. If, on the other hand, we choose to interpret one, or perhaps all three consonants in (41c), as not involving palatalisation, which seems best at least for $/ \mathrm{kac}^{\mathrm{h}} \mathrm{i} /$, then it is less obvious how the blocking mechanism can be expressed, as some other representation than a dependent $\mathrm{C}$ must be posited for a palatal consonant, so the latter can be distinguished from palatalisation (cf. the discussion in Section 4.1). It is not quite clear what this should be, given that a single $\mathrm{C}$ in the primary locational gesture represents a plain denti-alveolar apical coronal.

If it is not quite obvious how CV phonology can express this blocking mechanism, then it is evident that dependency phonology, at least in the version adopted here in particular with the extensions proposed by Staun (1996), can account for the blocking effect of the palatal consonants in a relatively straightforward way. Firstly, it is not necessary within this framework to encode palatal consonants in terms of a secondary specification to block the umlaut rule from applying. In terms of this model, the property which spreads is $|\mathbf{i}|$, and $|\mathbf{i}|$ is already part of the specification for palatals as appears from the association links in (31). The association links then predict that no spreading will occur in the Korean data in (43c), as the consonant which the $|\mathbf{i}|$-component has to spread across is specified for this property in the first place.

\subsubsection{Provisional results}

Having examined two types of place evidence, secondary articulation and the function of the latter as barriers, the pattern which begins to emerge is that stricturebased feature geometry and component-based dependency phonology, with the extensions proposed here, offer the best accounts of these place phenomena. In particular, the availability of a subjoined V-place node to account for secondary articulation is the pivotal property of the stricture-based feature geometry. This property not only allows for palatalisation and the possibility of expressing the transformation of a palatalised consonant to a full palatal via promotion. It is also this property which enables us to formulate why in the Korean example umlaut fails to occur. No pivotal property within dependency phonology seems to serve the same purpose to quite the same extent. Rather, it is the presence of the association links, in particular the association of palatality with $|\mathrm{i}|$ in this linking network, which enables to account for the two relevant phenomena. The reason why articulator- 
based feature geometry and CV phonology, the two competing models, offer less adequate accounts is that in the former secondary articulation is expressed in terms of the dorsal features [high], [low], [back] and [round] and not in terms of a subjoined V-place node, and that in the latter it is not quite clear how a pure palatal consonant should be represented and how it should be distinguished from a palatalised coronal and a plain apical denti-alveolar coronal.

\subsection{Vowel harmony}

We have now established a first general impression of the potentialities of the four representational models. But we want to establish a more complete picture. We promised earlier that we would examine the different vocalic place hierarchies against two backgrounds, viz. secondary articulation and vowel harmony in our attempt to reach a more complete picture. We looked at the former in the previous section. In this section we consider two instances of the latter, in particular a vowel harmony found in (Northern Penutian) Klamath and a vowel harmony found in (Finno-Ugric) Eastern Cherimis. Both instances of vowel harmony have been discussed by Odden (1991).

\subsubsection{Klamath}

Vowel harmony in Klamath, which is a language that has the vowels $/ \mathrm{i}, \mathrm{e}, \mathrm{\alpha}, \mathrm{o} /$, is a rule which spreads the place features of a vowel to certain prefixes such as the causative prefix $\operatorname{sn} V$. The data given by Odden are displayed in (42):

$\begin{array}{ll}\text { sna-batgal } & \text { 'gets someone up from bed' } \\ \text { sne-l'e:ml'ema } & \text { 'makes someone dizzy' } \\ \text { sne-ge:jiga } & \text { 'makes tired' } \\ \text { sno-bo:stgi } & \text { 'causes something to turn black' } \\ \text { sni-nklik'a } & \text { 'makes dusty' }\end{array}$

Odden's point about discussing these data is that they illustrate a weakness in the articulator-based framework. Because the latter subsumes the vowel place features under the dorsal node, as we saw earlier, this model predicts that the spreading of these features is blocked when the intervening consonant is a dorsal. But, as Odden points out, this prediction is not borne out by the data in (42). The dorsal velar in, for example, sne-ge:jiga does not prevent vowel harmony from occurring as it should. Odden then has a case for rejecting the articulator-based framework.

Rather than pursuing the conclusions which Odden draws from these data, let us instead consider how the models under consideration here can handle this harmony. Clements accounts for the harmony with his stricture-based framework (cf. Clements, 1991) by claiming that any vowel has a C-place specification above it, intervening between the root node and V-place. This explains an asymmetry in the way spreading occurs in consonants and vowels. According to Clements vowels can spread across an intervening consonant, whilst consonants do not spread across an intervening vowel, but only from one to another adjacent consonant (Clements, 1987). But this extra C-place specification not only explains such spreading restrictions; it also 
explains the Klamath data displayed in (42). Consider the representation for (the relevant part of) Klamath sne-ge:jiga:

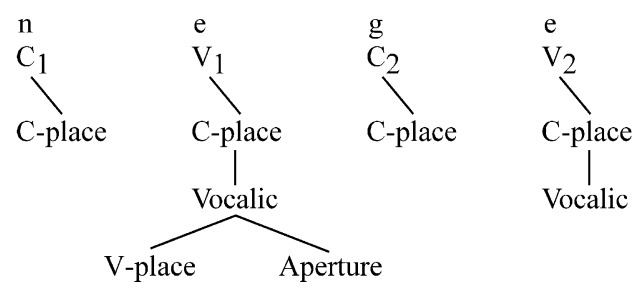

The spreading from $\mathrm{V}_{2}$ to $\mathrm{V}_{1}$ is possible because it does not have to cross a specification which could block it, as no feature hangs from $\mathrm{C}_{2}$ 's $\mathrm{C}$-place specification. Conversely, the spreading from $\mathrm{C}_{2}$ to $\mathrm{C}_{1}$ is blocked because this entails that a specification for the feature which spreads will have to cross a line with the relevant feature, i.e. C-place.

Let us now consider how CV phonology and dependency phonology can handle the Klamath data. sne-ge:jiga Is the critical example, in particular, the question is whether the intervening consonant in these two models is specified for the feature which crosses it. We specify the relevant part of sne-ge:jiga in (44), first in CV-terms and then in dependency terms:

$\begin{array}{lllll} & \mathrm{n} & \mathrm{e} & \mathrm{g} & \mathrm{e} \\ & \mathrm{C}_{1} & \mathrm{~V}_{1} & \mathrm{C}_{2} & \mathrm{~V}_{2} \\ \text { CV phonology } & & \mid \mathrm{C} & - & \mathrm{C} \\ \text { Dependency phonology } & & |\mathrm{i} ; \mathrm{a}| & \mathrm{Ve} & |\mathrm{i} ; \mathrm{a}|\end{array}$

In CV phonology the intervening consonant's articulatory specification is empty which, according to van der Hulst, is the appropriate way to represent dorsal consonants. Given this representation, harmonisation will not be blocked as the root vowel is not characterised by an empty articulatory specification. In dependency phonology the specification of the intervening consonant is not shared by the root vowel either. Thus both dependency phonology and CV phonology can account for the presence of umlaut in those cases where the intervening consonant is a dorsal.

Although they are able to account for Klamath harmonisation, the three models do not accomplish this result equally convincingly. CV phonology and dependency by and large allow for the harmonisation equally well. It is a problem, though, that in CV phonology the critical example sne-ge:jiga is represented in terms of an empty articulatory gesture, a representation which is problematical because it is not clear how it differs from the complete absence of an articulatory gesture which is also a possible representation within this framework. The account within stricture-based feature geometry hinges on the plausibility of inserting a C-place node between the segment node and the vocalic node in a vowel specification. Clements motivates this 
insertion with the claim, outlined earlier, that it helps to explain the asymmetry in the spreading behaviour of vowels and consonants. We cannot help finding this extra C-place node in vowels somewhat spurious when it only serves this specific purpose. Also it is not clear which of the two place nodes is the target node when a vowel has a C-place feature attached to it. Thus, it still remains to be seen that stricture-based account of Klamath vowel harmony is superior to one formulated within an articulator-based feature geometrical model.

The problematic case of sne-ge:jiga does not constitute a problem for dependency phonology. The vowel features which spread are $|\mathrm{i}|$ and $|\mathrm{a}|$ and the intervening consonant is not specified for these in the association links, so the prefix can assume the quality of the stem vowel. However sno-bo:stgi, by contrast, could be argued to pose a problem for this model. The components which spread here are $|\mathrm{a}|$ and $|\mathbf{u}|$ and the intervening labial consonant is specified for $|\mathrm{u}|$ in the association links. But spreading is not blocked. This is explicable in terms of which property of $|\mathbf{u}|$ that dominates, velar constriction or roundness. When it is associated with a labial it is the roundness property which dominates, but in a back vowel the velar constriction property is dominant, because roundness is the unmarked property of back vowels. Thus the vowel of the stem can pass unhindered.

\subsubsection{Eastern Cheremis}

The other instance of vowel harmony to be considered here is the harmony found in (Finno-Ugric) Eastern Cheremis, a harmony also discussed by Odden and which, among others, supports his repeated claim that Clements' stricture-based feature geometry is superior to articulator-based feature geometry. Eastern Cheremis is a language which has the following vowel inventory (cf. Maddieson, 1984, p. 274):

$$
\begin{array}{llll}
\mathrm{i} & \mathrm{y} & & \mathrm{u} \\
\mathrm{e} & \varnothing & \partial & \mathrm{o}
\end{array}
$$

The actual harmony in this language appears in, for example, the possessive suffix $z e$ whose vowel alternates between [e], [o] and [ø], depending on which vowel precedes it. The alternation is summarised in (46a) and data illustrating the harmonisation are displayed in (46b):
a) $[\mathrm{e}] \rightarrow[\mathrm{o}]$ after $[\mathrm{u}, \mathrm{o}]$
$[\mathrm{e}] \rightarrow[\mathrm{o}]$ after $[\mathrm{y}, \varnothing]$
$[\mathrm{e}]$ elsewhere i.e. after [i, e, ə, a]
b) surt-so 'his house' kit-se 'his hand'
boz -so 'his wagon' suzar-ze 'his sister'
yp-sø 'his hair' bokten-ze 'beside it'
sør-zø 'its milk'

We follow Odden and assume that the underlying vowel of the suffix is /e/. Stricturebased feature geometry can capture this harmonisation as spreading of the V-place node as shown: 




That is, within this framework Cheremis harmonisation involves the spreading of a node which does not specify aperture or opening, but only place and rounding. In this way it is possible to express that Cheremis harmonisation is just one process. By contrast, as Odden points out, the articulator-based version of feature geometry cannot allow for this harmonisation without either letting all dorsal features and labial spread or without accepting unrestricted spreading of individual features. Thus stricture-based feature geometry provides a more promising account (as in the Klamath case) than articulator-based feature geometry, because height constitutes an independent branch and does not hang from the same node as back. Such a feature organisation can directly capture the fact that Cheremis harmonisation is one rule.

But how will the component-based frameworks allow for the Cheremis data? Consider first an account formulated in dependency terms. In dependency phonology the change of $[\mathrm{e}] \rightarrow[\mathrm{o}]$ and $[\mathrm{e}] \rightarrow[\varnothing]$ both involve the $|\mathrm{u}|$-component solely, but in different ways. In the former, $|\mathbf{u}|$ takes over the role of the component $|\mathrm{i}|$, whereas in the latter it is added to the specification of the underlying suffix vowel. In (48a) and (48b), we give first the representations of the stem vowels and the affected suffix vowel as they would be represented within dependency phonology. (48c) And (48d) display the harmonisation of $[\mathrm{e}] \rightarrow[\mathrm{o}]$ and $[\mathrm{e}] \rightarrow[\varnothing]$, respectively:
(a)

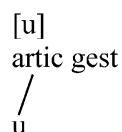

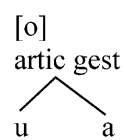
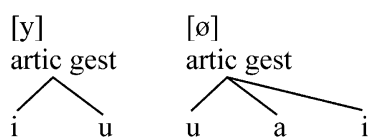
(b) $[\mathrm{e}]$<smiles>[3H][13CH]I</smiles>
(c)<smiles>[13CH][13CH]</smiles>
(d) $[\mathrm{y} / \varnothing]$ artic gest (a)

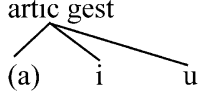

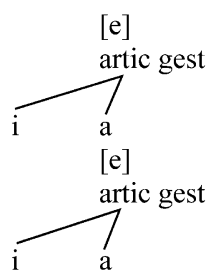

In (48c) harmonisation involves the attachment or subjunction of the $|\mathrm{u}|$-component to the articulatory gesture of [e] and the delinking of the $|\mathrm{i}|$-component. (48d), On the other hand, describes a situation where the $|\mathrm{u}|$ component of the root vowel is attached or subjoined to the articulatory gesture of [e] without the delinking of the 
|i|-component. Like stricture-based feature geometry, component-based dependency phonology can then capture the Cheremis harmonisation as a uniform process, viz. as spreading of the component $|\mathbf{u}|$.

Consider next how the same harmonisation is accounted for within CV phonology. In this model the stem vowels and the affected suffix vowel would receive the representations given in (49a) and (49b), whilst (49c) and (49d) represent the harmonisation of $[\mathrm{e}] \rightarrow[\mathrm{o}]$ and $[\mathrm{e}] \rightarrow[\varnothing]$, respectively, as $\operatorname{did}(48 \mathrm{c})$ and $(48 \mathrm{~d})$ :

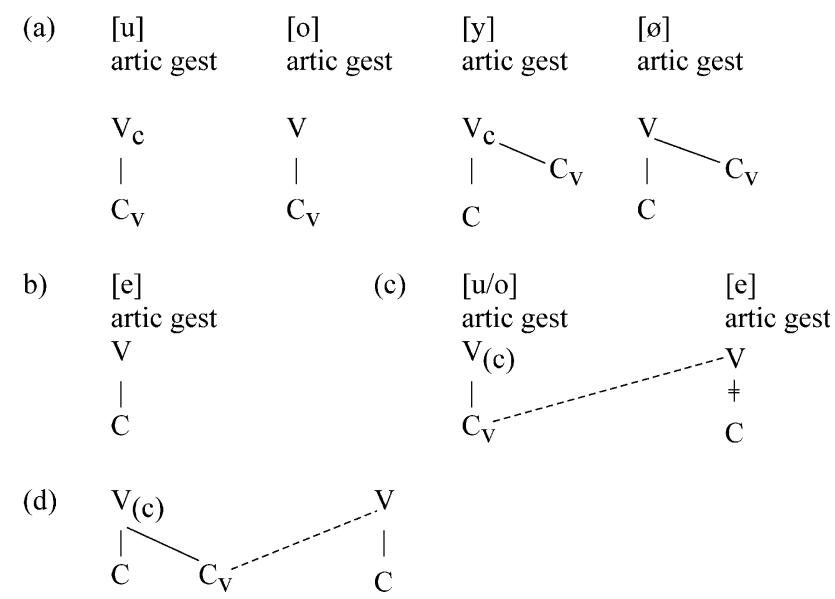

The harmonisation of [e] in $(49 \mathrm{c})$ involves the association of $\mathrm{C}_{\mathrm{v}}$ with the representation of the suffix vowel at the same time as the $\mathrm{C}$ of the latter is delinked. Similarly, the harmonisation in (49d) involves the association of $\mathrm{C}_{\mathrm{v}}$ with the suffix vowel, but - since the latter remains front - without the delinking of the dependent C. Because both backness and roundness are expressed in terms of one representation, viz. $\mathrm{C}_{\mathrm{v}}, \mathrm{CV}$ phonology, just like dependency phonology, has no difficulty in accounting for Cheremis vowel harmonisation in a uniform way.

Of the two feature geometrical models considered here, only Clements' stricture-based theory is able to offer a uniform account of Cheremis harmonisation. Unlike the articulator-based model, Clements' model organises aperture as one independent property and place and rounding together as another property. The articulator-based model, by contrast [cf. (4)] does not organise height separately, but instead it is a s-dependent of the dorsal node. At the same time labial (and then also rounding) is not linked with dorsal, but has independent node status. As a result, Cheremis harmonisation cannot be expressed as a single process in the articulator-based version of feature geometry. Only the organisation of stricture-based feature geometry allows for this possibility.

Turning to the two component-based models, it is clear that because they express backness and rounding in one component or one basic componential structure, both models can allow for the harmonisation in a simple and uniform way. It is true, they achieve this result in slightly different ways: dependency phonology in terms of the simplex structure $|\mathrm{u}|$ and $\mathrm{CV}$ phonology in terms of the more complex structure $\mathrm{C}_{\mathrm{v}}$. But they both capture the harmonisation. 


\subsubsection{Provisional summary of the results}

Let us now briefly attempt to establish what the vowel harmony evidence has shown about the applicability of the two types of model under consideration here. The picture which emerged on the basis of vowel height and secondary articulation, viz. that stricture-based feature geometry constitutes a well worked-out comprehensive system, is on the whole also confirmed by the vowel harmony evidence found in Klamath and Eastern Cheremis. The reservation, 'on the whole', refers to the fact that in order to account for Klamath harmonisation it is necessary to hypothesise that a node C-place is as much a part of a vowel representation as it is of a consonant representation. So before the validity of this extra C-place node is supported by further evidence, stricture-based feature geometry cannot be said to handle the harmonisation phenomena in a fully satisfactory way.

Applying dependency phonology and CV phonology to the vowel harmony evidence rehabilitates the latter and confirms the validity of the former. Recall that CV phonology had some difficulty in accounting for the vowel height phenomena (cf. Section 4.1), because of the absence within this framework of an independent node denoting 'aperture', and that both types of secondary articulation (cf. sub-sections 4.2.2 and 4.2.3) received no or only very poor accounts, because it is difficult to establish partly how a pure palatal consonant should be represented and partly how the latter should be distinguished from a palatalised coronal and a plain apical denti-alveolar coronal. But vowel harmony in Klamath and Eastern Cheremis rehabilitate $\mathrm{CV}$ phonology, in particular if it is accepted that empty representations are appropriate representations. CV phonology, just like dependency phonology, provides adequate and insightful accounts of these two harmony processes.

The general impression that stricture-based feature geometry and dependency phonology are able to provide insightful accounts, an impression which appeared after applying the two types of model to secondary articulation evidence (cf. subsections 4.2.2 and 4.2.3), is then further supported by the harmony evidence considered in the previous sections. By contrast, the impression we have of CV phonology has changed for the better after applying it to the harmony evidence. As just pointed out, $\mathrm{CV}$ phonology can express this as a $\mathrm{C}_{\mathrm{v}}$ harmony, whereas dependency phonology captures it as simple $|\mathbf{u}|$ harmony. This difference between these two accounts follows from the distinct claims the two models make about the form of the vowel space: that is, whether it is interpreted as triangular or whether it is interpreted as quadrangular. Attempting to evaluate the two interpretations of the harmony evidence, must then await a more general evaluation of these two interpretations of the vowel space.

\section{Three problematical phenomena}

Up until now our examination has shown that of the two feature geometrical models examined here, Clements' stricture-based model is superior to the articulator-based version developed and defended by among others Sagey and Halle. But a closer inspection reveals that the geometry and the associated features suggested 
by Clements may also in some cases create complications. One such complication follows from the claim that the place node branches into [labial], [coronal], [dorsal] and [radical]. Such a hierarchisation leads to the rejection of the feature [back] whose plus and minus values are replaced by the monovalent [dorsal] and [coronal] features respectively. In this section we examine three phenomena, a dissimilation process in English, a backness/roundness harmonisation in Turkish and some consonant constraints in Arabic, all three of which illustrate why it is problematical to bifurcate [back] into two monovalent features. We focus on this aspect of Clements' model because it serves as an appropriate entry to the more general purpose of establishing which representational model possesses the greater descriptive power. As a consequence, Sections 5.2 and 5.3 will deal with how the three phenomena can be accounted for by $\mathrm{CV}$ phonology and dependency phonology to provide the necessary background for comparison and assessment.

\subsection{The three phenomena and stricture-based feature geometry}

The first phenomenon is the well-known dissimilation found in some accents of English like, for example, general Australian English and London English (cf. Wells, 1982). In the closing diphthongs /a//and /av/ of these accents, the nuclei move away from the non-nuclei element as shown:

$$
\begin{aligned}
& / \mathrm{aI} / \rightarrow / \mathrm{aI} / \text { or } / \mathrm{DI} / \\
& / \mathrm{au} / \rightarrow / \mathfrak{} / \mathrm{W} /
\end{aligned}
$$

In stricture-based feature geometry such dissimilations will be described as an assignment of either [dorsal] or [coronal] to the V-place node. But such a description disguises the fact that front vowels and back vowels are opposites, unless [dorsal] and [coronal] are redefined as binary features such that [+ coronal] implies [ - dorsal]. But according to Clements [dorsal] and [coronal] are not binary; they are unary as the other features which hang from the place node. Accounting for the dissimilations in terms of these assignments, will then not express the polarisation of the shifts.

The second phenomenon which the split into [coronal] and [dorsal] cannot account for in a direct way is the Turkish vowel harmonisations in which the backness (and the roundness value) of many suffixes match that of the root vowel. Backness harmonisation is illustrated in (51). (51a) Illustrates the plural suffix -lar with a back vowel after a root vowel which is back, and (51b) the suffix -ler with a front vowel after a root vowel which is front:

$\begin{array}{llll}\text { (a) } & \text { kol } & \text { kol-lar } & \text { 'arm' } \\ & \text { kuz } & \text { kuz-lar } & \begin{array}{l}\text { 'daughter' } \\ \text { kul }\end{array} \\ & \text { kul-lar } & \text { 'slave' } \\ \text { (b) } & \text { yel } & \text { yel-ler } & \text { 'wind' } \\ & \text { göl } & \text { göl-ler } & \text { 'sea' } \\ \text { dis } & \text { dis-ler } & \text { 'tooth' }\end{array}$


When the difference between [-back] and [+ back] is expressed as [coronal] versus [dorsal], this correspondence between root vowel and suffix vowel is difficult to express, unless [coronal] and [dorsal] again are made binary and [+ coronal] again implies [-dorsal].

But then why not define [coronal] and [dorsal] as binary? Because from other evidence it is clear that [coronal] and [dorsal] are monovalent and that they do not have the same hierarchical tier status, nor behave identically with respect to complexity. This can be demonstrated on the basis of the third phenomenon which constitutes a problem for the stricture-based model of feature geometry. This phenomenon concerns consonant constraints in Arabic (cf. McCarthy, 1991). According to McCarthy there is a strong tendency in Arabic for adjacent consonants not to be produced with the same articulator. This constraint can be expressed as follows:

articulator tier $\quad *[\mathrm{x}][\mathrm{x}]$

where $[\mathrm{x}]=$ labial, dorsal, coronal. This constraint can also account for another co-occurrence restriction in Arabic which holds for the first and third consonants of a triconsonantal root. As McCarthy points out, if we are to account for this in terms of the constraint given in (52), then [labial], [coronal] and [dorsal] must be independent monovalent features and each define their own tier. To see this, consider how (52) would rule out a triconsonantal root like [fdb]. To block this, the intermediate [d] must somehow be transparent so the cluster is treated as biconsonantal. This can be achieved if we hypothesise a hierarchy such as that shown in (53):

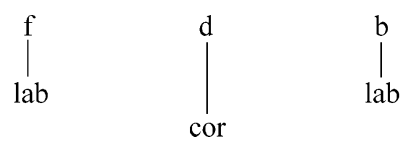

in which the individual feature [coronal] occupies a different tier expressed by its relatively lower position in the representation. Thus the Arabic evidence also supports the claim that the features [coronal] and [dorsal] act independently and that they cannot occupy the same hierarchical tier. In view of this status, it is difficult to maintain that the contrast [coronal]/[dorsal] is directly comparable with the binary contrast $[+$ back $] /[-$ back $]$, which clearly must belong to the same tier. Vowel harmonisation and vowel dissimilation also suggest that they are not directly comparable. Thus it is appropriate to conclude that, despite its obvious virtues in other respects, the hierarchy and the associated features suggested by Clements still have to undergo some refinement.

\subsection{The three phenomena reconsidered: dependency phonology}

Component-based dependency phonology provides perhaps one such refinement. In any case, the vowel dissimilations in broad Australian and London English can 
be described in this model in a simple way, viz. as shifts from $|\mathrm{a}|$ to $|\sim \mathrm{a}|$. It is true, this presupposes that the starting points in words like price and mouth have open central nuclei, i.e. that the shifts' point of departure is [a]. But since the non-broad or cultivated pronunciations have such a vowel, this interpretation of the shifts seems reasonably well-founded. Thus the shifts take either the $|\mathbf{a}|-|\mathbf{i}|$ 'path' resulting in [mæo $\theta$ ] (or with an even closer nucleus), or the $|\mathbf{a}|-|\mathbf{u}|$ 'path' resulting in [proIs]. Given the nature of the hierarchy outlined in Section 3.4, these polarisations can then be expressed uniformly as moving away from $|\mathrm{a}|$, i.e. as in increase, if you like, of $|\sim \mathrm{a}|$. The direction either towards $|\mathbf{i}|$ or towards $|\sim \mathrm{i}|$ emphasises the opposite nature of the two shifts.

The Turkish vowel harmonisation data do not appear to be as directly expressible as the English data, however. This harmonisation affects suffixal vowels which either harmonise with the root vowel with respect to backness, as shown in (51), or - in the case of accusative suffixes if the vowel is also high - with respect to backness and roundness. Data illustrating the latter type of harmonisation are displayed in (54):

\begin{tabular}{llll}
\multicolumn{3}{c}{ accusative } & \multicolumn{2}{c}{ accusative } \\
kol & kol-u 'arm' & yel & yel-i 'wind' \\
kul & kul-u 'slave', & dis & dis-i 'tooth' \\
kuz & kwz-u'daughter' & gül & gül-ü 'rose' \\
& & göl & göl-ü 'sea'
\end{tabular}

But how will dependency phonology account for such a harmonisation when it does not employ variable binary features which, if alpha-specified, could allow for this harmonisation in a simple way, viz. as [aback] and, if the suffixal vowel is also high, [ $\alpha$ round]? Let us consider backness harmonisation first.

In dependency phonology the back vowels [u, u, o, a], which produce the back vowel suffix -lar, have either the component $|\mathrm{a}|$ or $|\mathrm{u}|$ or both in their articulatory representation. In addition, there is one vowel, viz. [u], which contains the component $|\sim \mathrm{a}|$ plus $|\mathrm{u}|$, a combination which was contemplated in Section 3.4 as one appropriate representation for a high, back unrounded vowel. The front vowels [i, ü, $\mathrm{e}, \mathrm{o}]$, on the other hand, which induce the front vowel suffix -ler, all contain the component $|\mathbf{i}|$. In addition, they contain $|\mathrm{a}|$ if the vowel is non-high and $|\mathrm{u}|$ if it is high and also round. These vowel representations are shown in (55):

$\begin{array}{llllll}\text { a. } & {[\mathrm{u}]} & |\mathrm{u}| & \mathrm{b} & {[\mathrm{i}]} & |\mathrm{i}| \\ & {[\mathrm{u}]} & |\mathrm{u}, \sim \mathrm{a}| & & {[\ddot{\mathrm{u}}]} & |\mathrm{i}, \mathrm{u}| \\ & {[\mathrm{o}]} & |\mathrm{a} ; \mathrm{u}| & & {[\mathrm{e}]} & |\mathrm{i}, \mathrm{a}| \\ & {[\mathrm{a}]} & |\mathrm{a}| & & {[\ddot{o}]} & |\mathrm{i}, \mathrm{a}, \mathrm{u}|\end{array}$

but the question is also whether these representations permit unique class representations. The set in (55b) does not pose a problem. It can be specified as $\{\mathrm{i}\}$ where the braces, rather than vertical bars, reflect that the sound or sounds enclosed in these 
minimally contain the component $|\mathbf{i}| .|\mathrm{i}|$ is minimally shared by all the vowels in (55b) but does not exhaust the representation, hence the brace-notation is appropriate.

It is more difficult to set up a class representation for the set of vowels given in (55a). The occurrence of $[a]$ in the set excludes a class representation in terms of $\{u\}$. Likewise, the occurrence of $[\mathrm{u}]$ and $[\mathrm{u}]$ excludes the abbreviation $\{\mathrm{a}\}$. But an adequate class representation is possible if we employ negated components. We proposed in section 3.4 that negation is involved in two of the basic vowel components, in that $|\mathrm{i}|$ and $|\mathrm{u}|$ strictly speaking are abbreviations of $\left|\sim \mathrm{a}^{\mathrm{i}}\right|$ and $\left|\sim \mathrm{a}^{\mathrm{u}}\right|$. The latter representations are the result of a desire to specify vowels which are non-low and high front and non-low and high back, respectively. It the present case we want to express a set of vowels which are non-front, but which may be high and low. Nonfrontness must involve the opposite representation of front vowels. A moment ago we specified the class of front vowels as $\{i\}$. In view of this, back vowels, like the set given in (55a), could then be specified as $\{\sim \mathrm{i}\}$, i.e. as the class which as a minimum contains one component which is not $|\mathbf{i}|$. Strictly speaking, the specification $\{\sim \mathrm{i}\}$ is an abbreviation of negated $\left\{\sim \mathrm{a}_{\mathrm{i}}\right\}$, given that $|\sim \mathrm{i}|$ is an abbreviation of $\mid \sim \mathrm{a}_{\mathrm{i} \mid}$. But this does not lead to a double negation of $|\mathrm{a}|$ and hence an increase in closeness, since in $\{\sim \mathrm{i}\}$ the scope of the negation is not confined to $\{\sim \mathrm{a}\}$, but encompasses everything enclosed by the braces, cf. $\sim\left(\left\{\sim \mathrm{a}_{\mathrm{i}}\right\}\right)$.

Representing the two classes of vowels in (55a) and (55b) as $\{\sim \mathrm{i}\}$ and $\{\mathrm{i}\}$, respectively enables us to characterise the Turkish backness harmonisation presented in (51). This may be formulated as shown in (56), which, as in (52) above, specifies which structures are blocked from occurring in Turkish:

$$
\begin{aligned}
& \text { *root- } \mathrm{V}_{1} \quad \mathrm{C} \quad \text { suffix-V } \\
& \text { a) } \mathrm{V}_{1}=\{\mathrm{i}\}, \mathrm{V}_{2}=\{\sim \mathrm{i}\} \\
& \text { b) } \mathrm{V}_{1}=\{\sim \mathrm{i}\}, \mathrm{V}_{2}=\{\mathrm{i}\}
\end{aligned}
$$

According to (56) the root vowel and the suffix vowel must agree with respect to the $|\mathrm{i}|$-value, negated or not negated, but that this is not necessarily the only component which is found in the specification. If this agreement does not occur, the structure is ill-formed.

But the dependency model should also be able to cover the harmonisation which involves not only backness but also rounding. This harmonisation occurs in accusative forms with high suffix vowels, as in the data displayed in (54). From (54) it can be seen that high vowels in the accusative suffixes in Turkish harmonise in rounding with the root vowel. In a SPE-type of framework, this correspondence would be expressed in terms of the alpha notation, in particular as $\alpha$ [round] and [+ high]. But this solution is not available within a framework which employs unary components.

In fact, the first condition that the suffix vowel should be a high vowel, is a condition which, as was shown earlier, can be allowed for directly, viz. as $|\sim a|$. And in point of fact the rounding harmonisation is built into the formulation given in (56). This follows from the notational implications of the curly brackets. $\{i\}$, For example, 
refers to any vowel specified for $|\mathrm{i}|$ (in the language in question) plus whatever other components, if any, are needed to distinguish this $|\mathrm{i}|$-vowel. Thus, if $\mathrm{V}_{1}$ is specified as $\{\mathrm{i}\}$, then it can also have $|\mathrm{u}|$ in it, as is the case in [ü], and according to (56) rounding will then also occur in the suffix vowel. Similarly, if $V_{1}$ is specified as $\{\sim i\}$, which is relevant for [u], an unrounded vowel, no rounding occurs in the suffix vowel, because $\{\sim \mathrm{i}\}$ specifies a vowel which does not contain $|\mathrm{i}|$ which is a characteristic found in, among others, unrounded back vowels.

The properties available within the component-based dependency model thus enable us to account for vowel harmonisation in Turkish, even though the alpha notation is inapplicable to a component-based model. The dependency notation is also able to express Cockney dissimilation. The fact that $|\mathrm{a}|$ allows to be negated enables us to capture this polarisation in terms of an increase of $|\sim \mathrm{a}|$. But the third phenomenon, restrictions on consonant combinations in Arabic, should also receive a straightforward account in dependency-terms. Let us then once again return to this phenomenon.

To recapitulate, the restriction on consonant combinations in Arabic involves a constraint against two adjacent consonants produced with the same articulators, as expressed in (50). But as McCarthy points out (McCarthy, 1991), this constraint can also act as a device for blocking the occurrence of identically articulated first and third consonants in triconsonantal roots. As shown in (51), the triconsonantal root [fdb] can be ruled out by the rule in (50), provided the intermediate [d] somehow has a different status than [f] and [b]. Stricture-based feature geometry can allow for this special status, because [labial], [coronal] and [dorsal] act independently and moreover form an internal hierarchy in which [coronal] occupies a position different from that of [labial] and [dorsal]. The problem with this analysis is that it is impossible to maintain that [dorsal] and [coronal] are comparable to [+ back] and [-back], if [dorsal] and [coronal] are differently ordered hierarchically.

For dependency phonology this constraint should be fairly straightforward to account for, given the hierarchy outlined in (31) above. The articulatory specifications of the three consonants in the triconsonantal root [fdb] will involve two labial values, one for each of [f] and [b]. The value of the intermediate [d], on the other hand, is denti-alveolar. It is the contention of the model outlined in (31) that this is the least complex of the C-place types (cf. Staun, 1996, see also Paradis and Prunet, 1991). As less complex than [labial], the intermediate denti-alveolar [d] can be argued to be transparent and the illegitimacy of [fdb] explained as a violation of the general constraint on adjacent consonants. But most importantly, and this is how the dependency account differs from the account within stricture-based feature geometry, accounting for illegitimacy of [fdb] in this way does not clash with other hypotheses about which features correspond to [+ back] and [-back].

\subsection{The three phenomena reconsidered: CV phonology}

It only remains now to investigate how CV phonology can allow for the three phenomena discussed in the previous sections. We consider first vowel dissimilation in English. In CV-terms the two polarisations [cf. (50)] must involve something like the following (only the nuclear (changing) elements are represented in CV-terms): 


\begin{tabular}{|c|c|c|c|c|}
\hline /aI/ & $\rightarrow$ & $/ \mathrm{DI} /$ & /av/ & $\rightarrow$ \\
\hline V & $\rightarrow$ & $\begin{array}{l}\mathrm{V} \\
! \\
\mathrm{C}_{\mathrm{v}}\end{array}$ & $\mathrm{V}$ & $\rightarrow$ \\
\hline
\end{tabular}

But do $\mathrm{V} \rightarrow \mathrm{C}_{\mathrm{v}}$ versus $\mathrm{V} \rightarrow \mathrm{C}$ (in (57) ' $\rightarrow$ ' means 'changes to' and not 'governs') actually represent opposite directions? Not in an any more apparent way than [dorsal] versus [coronal] represent opposite poles, and the latter do so only if they are redefined as binary features such that [+ coronal] implies [-dorsal]. Thus as long as it employs i-dependent $\mathrm{C}$ and i-dependent $\mathrm{C}_{\mathrm{v}}$ to express back versus front, $\mathrm{CV}$ phonology will face the same problem as stricture-based feature geometry, viz. fail to express the polarisation of the shifts in a direct way.

Stricture-based feature geometry also had difficulty accounting for the Arabic consonant constraints. For example, it had difficulty accounting for the illegitimacy of the triconsonantal root [fdb], because [dorsal] and [coronal] correspond to [-back] and [+ back]. Does CV phonology encounter the same problems? Recall first how labial, coronal and dorsal consonants are represented in CV phonology. These were listed in (32). Given these representations, the constraint against [fdb] could be argued to follow from the simple representation assigned to coronals, i.e. that these are simply $\mathrm{C}$ whilst the labial consonants are $\mathrm{C}_{\mathrm{v}}$. This appears from (58):

$$
\begin{array}{ccc}
\text { labial } & \text { coronal } & \text { labial } \\
\mathrm{C}_{\mathrm{v}} & \mathrm{C} & \mathrm{C}_{\mathrm{v}}
\end{array}
$$

However, the transparency of the coronals would be even more obvious if coronal consonants were assigned an empty representation. But among consonants this representation is reserved for dorsal consonants, a representation which, according to van der Hulst, is supported by the facts that dorsal is the 'weakest place' of articulation and that dorsal 'often forms the last phase in reduction processes before total debuccalisation occurs, or the easiest target for weakening' (1994, p. 458).

Thus, CV phonology does not encounter the same problems as stricture-based feature geometry. But instead it may be argued that it is a problem that the CV representation single $\mathrm{C}$ for coronal consonants and the empty representation for dorsal consonants, however appropriate these may be, clash with the general agreement, which is built into the dependency representation, and documented in detail by for example, Paradis and Prunet (1991), that coronal is the unmarked or least complex place of articulation for consonants. How this property could be incorporated into the system of $\mathrm{CV}$ phonology as it is summarised in (32) is not clear. And its failure to express this is an indication that the use of the empty representation for dorsals is in more than one way a problematical solution.

Let us now consider the two Turkish vowel harmonisations: backness harmonisation [cf. (51)] and accusative suffix harmonisation [cf. (54)]. Recall that backness harmonisation involves harmonisation between the vowel of the plural suffix and the vowel of the root: if the root vowel is front the suffix vowel is front and if the root vowel is back the suffix vowel is back. As pointed out in section 5.2, this harmonisation 
receives an obvious interpretation in terms of alpha-specified binary features. But again such a solution is not available when the basic components are unary as in $\mathrm{CV}$ phonology. Given that front vowels have dependent $\mathrm{C}$ and back vowels have dependent $\mathrm{C}_{\mathrm{v}}$, this harmonisation can be expressed as follows:

$$
\begin{aligned}
& \text { root }-\mathrm{V}_{1} \quad \mathrm{C} \quad \text { suffix }-\mathrm{V}_{2} \\
& \mathrm{~V}_{1}=\rightarrow \mathrm{C}_{(\mathrm{v})}, \mathrm{V}_{2}=\rightarrow \mathrm{C}_{(\mathrm{v})}
\end{aligned}
$$

which specifies that the root and the suffix vowel must agree either such that they both contain a dependent $\mathrm{C}$ or both contain a dependent $\mathrm{C}_{\mathrm{v}}$.

It is more difficult to represent the accusative suffix harmonisation, however. This type of harmonisation involves not only backness harmonisation but also roundness harmonisation if the root vowel is high. But this harmonisation applies to high rounded and high unrounded vowels alike. Thus, as appears from (56), if the root vowel is high and round, a high and rounded vowel will appear in the suffix, and if it is high and unrounded (i.e. [u]) a high and unrounded vowel will appear in the suffix. The problem is how to characterise this set of high root vowels, i.e. the set which appears in (54).

In CV phonology high vowels may be characterised as the set of vowels which has dominant $\mathrm{V}_{\mathrm{c}}$, whereas rounded back vowels may be identified as the set of vowels which has dependent $\mathrm{C}_{\mathrm{v}}$ and front vowels as the set of vowels which has dependent C. The last group, unrounded back vowels, constitutes a problem, however. van der Hulst does not assign a representation to this vowel type. One way of constructing an appropriate representation would be to start from the representation for $/ \mathrm{u} /$, i.e. $\mathrm{V}_{\mathrm{c}} \rightarrow \mathrm{C}_{\mathrm{v}}$, and then strip it of its rounding. $\mathrm{V}_{\mathrm{c}}$ then remains, but unfortunately $\mathrm{V}_{\mathrm{c}}$ is the only basic category which, according to van der Hulst, cannot occur alone. We must then look for an alternative, in particular consider whether other high vowel representations constitute suitable alternatives.

One such could be the representation proposed for high central vowels such as unrounded high central $/ \dot{\mathbf{t}} /$. In $\mathrm{CV}$ phonology high central vowels are associated with an empty locational gesture. Let us for a moment accept that this is an appropriate representation, despite the uncertain status of an empty locational gesture vis-à-vis an absent locational gesture, as pointed out earlier. If high central vowels are associated with an empty locational gesture, then the representation for high central $/ \mathbf{i} /$ in the Nimboran system considered earlier (cf. section 3.4) should be an empty locational gesture, whilst Nimboran /i/ should be assigned the representation $\mathrm{V}_{\mathrm{c}} \rightarrow \mathrm{C}$. With / $\mathrm{u} /$, which is also found in Nimboran, it is more difficult. The fact that it is high and unrounded and non-front, suggests that an empty representation would be appropriate for this vowel too. However, it must involve more than just this in order to be distinguished from $/ \dot{\mathbf{t}} /$. What this extra property should be is not obvious. But the representation for $/ \mathrm{u} /$ might provide us with a clue. As pointed out above, if $/ \mathrm{u} /$ is stripped of its roundness $\mathrm{V}_{\mathrm{c}}$ remains, and $\mathrm{V}_{\mathrm{c}}$ might well be the property which we lack and could assign to the secondary locational gesture. The problem is just that this possibility is excluded by van der Hulst who states $(1994$, p. 460$)$ that $V_{c}$ only occurs in combination with one of the basic 
categories listed in (15) as a dependent. Thus the following three representations are rather speculative for the Nimboran three-way distinction and not ones advocated by van der Hulst:

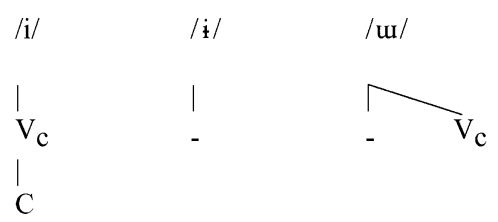

In other words, it is difficult to see how van der Hulst would capture this three way distinction in Nimboran when the representation for / $\mathrm{w} /$ given in (60) is barred. But as far as the Turkish data are concerned, it may be that it is unnecessary to operate with the 'illegal' representation for $/ \mathrm{w} /$ shown in (60). In view of the fact that there are no other high central vowels contrasting with /u/ in Turkish, the representation empty locational gesture could be argued to suffice phonologically. If we accept this, then the question is how such a representation for $/ \mathrm{u} /$ could be conflated with the other vowel representations to capture the class of vowels undergoing accusative suffix harmonisation.

In fact, it is quite simple to answer this question. When the class of high vowels receives two very different representations $\left(\mathrm{V}_{\mathrm{c}}\right.$ and empty locational gesture depending on whether they are peripheral or central), it is a clear that it is very difficult to posit such a common representation. Even the remaining vowels (high front and high rounded back vowels) are difficult to conflate in one class. The Turkish accusative harmonisation phenomenon then presents serious difficulties to CV phonology, whatever its other virtues.

The virtues of CV phonology thus fail to surface when it is applied to the three phenomena considered in this section. The vowel dissimilation in English receives no direct description, because the $\mathrm{CV}$ interpretation of front versus back vowels fails to express in an obvious way that the two classes are opposites. Similarly, the consonant constraints in Arabic fail to receive an explanation, because dorsal rather than coronal consonants are interpreted as the least complex consonantal place type by virtue of being associated with an empty locational gesture representation. And finally, CV phonology cannot offer a fully satisfactory account of the Turkish harmonisation processes, because it is unclear how high unrounded vowels should be interpreted and then also how this type of vowel may be incorporated in the class of vowels which undergo accusative harmonisation.

\subsection{The three phenomena: summary}

Let us now sum up the main points following from the application of the three representational models to English dissimilation, Turkish vowel harmony and Arabic consonant constraints. Our point of departure was that an account of these three phenomena would present a problem to especially stricture-based feature geometry. This prediction held true for dissimilation and harmonisation, but consonant constraints in 
Arabic received a straightforward account within this model due to the simplex status assigned to coronals. Its failure to account for the two other phenomena was due to the fact that it is not obvious that the two unary features, [coronal] and [dorsal], represent opposite poles. As such they do not express the polarisation of dissimilation in English, nor that the vowel harmony in Turkish actually involves harmonisation of two opposites values to one.

CV phonology can be criticised for facing the same kind of problem. The representations posited within this model for the distinction front versus back do not reflect that these are opposites. And for the same reason they cannot reflect that the Turkish vowel harmonisation involves harmonisation of one opposite value to another. Unlike stricture-based feature geometry, CV phonology faces the additional problem of not being able to explain why transparency plays a vital part in the Arabic consonant constraints. This requires that coronals are simplex, but in $\mathrm{CV}$ phonology this status is assigned to dorsals.

Applying dependency phonology to the three phenomena leaves us with fewer problems than were encountered by stricture-based feature geometry and CV phonology. Both dissimilation in English and Turkish vowel harmonisation receive straightforward descriptions in dependency terms. The use of in particular negated vowel components plays a crucial part in this success. $|\sim \mathrm{a}|$ plays the main part in the characterisation of dissimilation, whereas both $|\sim \mathrm{a}|$ and $|\sim \mathrm{i}|$ serve to characterise the classes of vowels undergoing harmonisation. But the consonant constraints in Arabic are also capturable unlike in both stricture-based feature geometry and CV phonology. The fact that coronals hold the status as least complex place type in dependency phonology is the central property in this description. One question remains to be answered, however: the extent to which it is appropriate to employ negated components. Does it make sense to negate a phonological primitive which is unary and which as such only takes on one form or is absent? The absence of a fully adequate answer to this question is the most serious objection which may be raised against this representational model.

\section{Summarising the results}

The object of this study has been to compare two types of phonological representation model. The first is the feature geometrical type, exemplified by stricturebased feature geometry and articulator-based feature geometry, and the second is the component and dependency-based type exemplified by $\mathrm{CV}$ phonology and dependency phonology. More particularly, the object of the study has been to attempt to establish which of these main types, and further which sub-type within the two main types of representation, is the more adequate. This object we have sought to achieve by applying the two main types of model to two sets of data. Firstly to a set of material which involves vowel height, secondary articulation and vowel harmony, and secondly to a set of material which comprises dissimilation in English, Turkish vowel harmonisation and consonant constraints in Arabic. Let us begin this conclusion with a summary of the results following from applying 
stricture-based feature geometry (stricture FG), dependency phonology (dependency) and $\mathrm{CV}$ phonology $(\mathrm{CV})$ to the first set of data. This is given in (61):

stricture FG dependency CV

vowel height
secondary articulation I
secondary articulation II
vowel harmony: Klamath
vowel harmony: Eastern Cheremis

$\begin{array}{lll}\sqrt{ } & \sqrt{ } & \div \\ \sqrt{ } & \sqrt{ } & \div \\ \sqrt{ } & \sqrt{ } & (\sqrt{ }) \\ (\sqrt{ }) & \sqrt{ } & (\sqrt{ }) \\ \sqrt{ } & \sqrt{ } & \sqrt{ }\end{array}$

It should be emphasised that (61) presents the results of these applications only in a very general way and leaves out many details. The symbol ' $\sqrt{ }$ ' indicates that the application is predominantly successful, whereas the symbol ' $\div$ ' indicates that the application of the representational model has failed to account for the phenomenon in question. The third possibility, ' $\sqrt{ }$ ' enclosed in brackets, specifies that the relevant representational model offers an account of the relevant phenomenon, but that this account involves the use of a problematical or criticisable aspect of the representation or that it offers only a partially satisfactory description.

It is evident from this summary that no matter whether the representational model applied to the data listed in (61) is stricture-based feature geometry or dependency phonology, the application leads to the same result: a satisfactory account of all five phenomena. It is equally clear that for $\mathrm{CV}$ phonology the matter looks somewhat more gloomy. CV phonology only offers one fully satisfactory account, viz. of vowel harmony in Eastern Cheremis, whilst for the remaining four phenomena it is either unable to account for them or offers only a partially satisfactory account.

The failure of CV phonology to account fully for all but two of the phenomena listed in (61) can be ascribed to the following properties of the framework. Firstly, the interpretation of the vowel space is not such that vowel raising receives a natural expression. In particular, it cannot express that raising involves a gradual increase/ decrease of a particular property. Secondly, the representational status of secondary articulations like palatalisation and velarisation remains somewhat unclear. In particular, no representation is offered for the latter and how the former should be distinguished from palatals proper remains unexplained. Thirdly, a distinction is drawn between an empty and an absent locational gesture, a distinction which is put to use in differentiating certain central vowels $(/ \mathbf{i} /$ versus $/ \mathbf{a} /)$. But how it is possible to distinguish between 'degrees' of emptiness and how the phonetic interpretation can handle such a difference remain unexplained. In addition, in the consonant description the empty locational gesture is used for dorsals. But as the simplest representation, it would be more natural to let the empty locational representation stand for the least complex class of coronals.

By contrast, neither stricture-based feature geometry nor dependency phonology faces the problems which $\mathrm{CV}$ phonology encounters. Their ability to account for the first 
phenomenon of vowel height is due to the presence in both models of two properties. Partly a structural device (node or component) which refers independently to vowel height and partly a property which directly expresses the scalar nature of vowel height. Their ability to allow for secondary articulation evidence follows from the clear distinctions which are drawn between primary and secondary articulations, but such that a primary articulation and the corresponding secondary articulation share important properties. In this way blocking mechanisms receive an obvious explanation.

The reason that only dependency phonology may be said to account well for Klamath vowel harmonisation is that this model need not resort to any extra or spurious representational device to allow for both phenomena. No problematical empty representation is needed to ensure that blocking does not take place. Nor is it necessary to posit a consonantal place representation to be part of a vowel description. It is sufficient to employ the existing properties of the locational description of vowels and the locational description of consonants. In the last harmonisation no account can be said to be better than any other. All three models possess the necessary representational capacity to allow for this in a simple and straightforward way.

But is this general impression established on the basis of the first set of data also borne out by the second set of data, the data involving dissimilation in English, vowel harmony in Turkish and consonant constraints in Arabic? We may summarise the result of applying stricture-based feature geometry, dependency phonology and $\mathrm{CV}$ phonology to these three phenomena as shown in the overview in (62):

$\begin{array}{lccc} & \text { stricture FG } & \text { dependency } & \text { CV } \\ \text { dissimilation in English } & (\sqrt{ }) & (\sqrt{ }) & (\sqrt{ }) \\ \text { vowel harmony in Turkish } & (\sqrt{ }) & (\sqrt{ }) & \div \\ \text { consonant constraints in Arabic } & \sqrt{ } & \sqrt{ } & \div\end{array}$

In fact, judging from (62) a pattern similar to that emanating from (61) begins to emerge. CV phonology again seems to be struggling. It has great difficulty accounting for two of the phenomena, whilst the third (dissimilation) is only allowed for in part. Its failure to allow for vowel harmony in Turkish follows from its inability to allow fully for the class of root vowels whose properties spread to the following suffix vowel. Specifically, characterising / $\mathrm{u} /$ and positing a class description for a set of back vowels which comprises this vowel constitutes a problem for CV phonology. The model's failure to characterise the constraints on consonant combinations in Arabic is due to the fact that the class of coronals is not assigned the status of least complex place type.

But dependency phonology and stricture-based feature geometry clearly only fare slightly better than CV phonology. Both models offer good accounts of the consonant constraints in Arabic. Dependency phonology because it assigns the least complex representation to coronals and stricture-based feature geometry because coronals occupy a different tier which also reflects the simplex status of this consonant type. However, for both models dissimilation in English and Turkish vowel harmonisation 
pose a problem, more so for stricture-based feature geometry perhaps than for dependency phonology. As regards stricture-based feature geometry, the problem is that the two phenomena have to be accounted for in such a way that [dorsal] and [coronal] express opposite poles. But given that they are defined as unary components and thus there is no way of to saying that, for example, [+dorsal] implies [-coronal], the polarisation involved in both the dissimilation process and the vowel harmonisation process fails to receive an obvious interpretation.

For dependency phonology the case is similar and yet not quite identical. The dependency components are also unary like [dorsal] and [coronal], but unlike the latter the dependency components are allowed to be negated. This property permits us to express the polarisation involved in both the dissimilation and the harmonisation instances in question. However, quite clearly it is somehow counterintuitive to allow unary components to be negated. Negating a value presupposes that the nature of the primitive is such that it can assume more than one value and it is precisely the nature of the unary component that it can have one value when it is present or be absent. This is the reason that we have reservations about the account offered within a dependency-based representation. Nonetheless, negated components have been widely used by dependency phonologists in connection with the three vowel components $|\mathrm{i}|$, $|\mathbf{u}|$ and $|\mathbf{a}|$. Because they make up a closed system with $|\mathrm{a}|$ as the most basic and as the component which serves as a link between the other two, the value of a negated component can be restricted and easily determined.

The general picture which emerges is that CV phonology with regard to the data considered in the previous sections fares worst. Stricture-based phonology's account has more to offer and dependency phonology provides an even better solution. But the success of dependency phonology hinges much on the adequacy of employing negated vowel components. If this procedure is accepted then much of its success can be ascribed to the appropriateness of interpreting the vowel space as a triangular system with three basic unary components, each defining an end point. And conversely the problems encountered by both stricture-based feature geometry and CV phonology can be put down to letting the vowel space have a quadrangular form, and at the same time maintaining that poles such as front versus back should be described in terms of monovalent components. For CV phonology the dropping of the triangular view follows naturally from operating with only two basic unary components, but no matter how adequate this change may be for other parts of the description of the internal structure of segments, it is not cost-free when it comes to the description of the phonology of vowels. For stricture-based feature geometry the adoption of a quadrangular view follows from the tradition on which this model is based, which was formed by the standard work of SPE, but the adherents of stricture-based feature geometry have not taken the full step and introduced a triangular view of the vowel space, even though the employment of unary components invites such a change of view.

In conclusion, the contest for representational superiority seems to stand between two strategies: a reductionist strategy which seeks to limit the number of ultimate phonological constituents to a minimum and an organisational strategy which seeks to find the phonetically and phonologically optimal feature hierarchy. The latter 
accepts a multiplicity of features but requires few and explicit hierarchical units. The former requires few ultimate constituents but accepts a multitude of structured combinations. For the description of the phonology of vowels both types of strategy lead to adequate results. But the most rigid reductionist strategy represented by $\mathrm{CV}$ phonology cannot be said to lead to the maximally adequate description. Allowing only two constituents is too constrained and the compensation that empty representations also constitute natural options requires further justification. Nor can the highly constrained hierarchical model represented by stricture-based feature geometry provide a fully adequate description. Adopting unary features in a basically quadrangular interpretation of the vowel space presents one problem. Another is the too extensive use - in an otherwise constrained theory-of a C-place node in a locational description of vowels. At the present stage in the development of feature theory the reductionist strategy in the form of dependency phonology offers the best description of the phonology of vowels. It is slightly less constrained than CV phonology, it does not combine unary components with a quadrangular interpretation of the vowel space and it avoids operating with more than one empty representation. This does not mean that we cannot point to problematical aspects of this model. One obvious problem is its use of negated unary components. This use requires further examination before the epithets highly adequate and applicable may be used to describe this model.

\section{References}

Anderson, J.M., 1980. On the internal structure of phonological segments: evidence from the history of English. Folia Linguistica Historica 1, 165-191.

Anderson, J.M., Ewen, C.J., 1987. Principles of Dependency Phonology. Cambridge University Press, Cambridge.

Anderson, J.M., Jones, C., 1974. Three theses concerning phonological representations. Journal of Linguistics $10,1-26$.

Anderson, J.M., Jones, C., 1977. Phonological Structure and the History of English. North Holland, Amsterdam.

Calabrese, A., 1987. The interaction of phonological rules and filters in Salentino. NELS 17, 1. 79-88.

Chomsky, N., Halle, M., 1968. The Sound Pattern of English. Harper and Row, New York.

Clements, G.N., 1987. The geometry of phonological features. Phonology 2, 225-252.

Clements, G.N., 1991. Place of articulation in consonants and vowels: a unified theory. Working Papers of the Cornell Phonetics Laboratory 5, 77-123.

Clements, G.N., Hume, E.V., 1995. Internal organisation of speech sounds. In: Goldsmith, J. (Ed.).

Ewen, C.J., 1980. Aspects of Phonological Structure. PhD dissertation, University of Edinburgh.

Halle, M., 1992. Phonological features. In: Bright, W. (Ed.), International Encyclopaedia of Linguistics, vol. 3. Oxford University Press, Oxford, pp. 207-212.

Hume, E.V., 1990. Front vowels, coronal consonants, and the rule of umlaut in Korean. Proceedings of NELS 20, 230-243.

Hume, E.V., 1992. Front Vowels, Palatal Consonants, and their Interaction in Nonlinear Phonology. PhD dissertation, Cornell University.

Jakobson, R., Fant, G., Halle, M., 1952. Preliminaries to Speech Analysis. MIT Press, Cambridge MA. Kaze, J., 1991. Metaphony and two models for the description of vowel systems. Phonology 8, 163-170. Ladefoged, P., 1971. Preliminaries to Linguistic Phonetics. Chicago University Press, Chicago.

Lass, R., 1976. English Phonology and Phonological Theory. Cambridge University Press, Cambridge. Lass, R., 1984. Phonology. Cambridge University Press, Cambridge. 
Lass, R., Anderson, J.M., 1975. Old English Phonology. Cambridge University Press, Cambridge.

Maddieson, I., 1984. Patterns of Sound. Cambridge University Press, Cambridge.

McCarthy, J., 1988. Feature geometry and dependency: a review. Phonetica 43, 84-108.

McCarthy, J., 1991. The phonetics and phonology of Semitic pharyngeals. In: Keating, P. (Ed.), Papers in Laboratory Phonology III: Phonological Structure and Phonetic Form. Cambridge University Press, Cambridge.

Odden, D., 1991. Vowel Geometry. Phonology 8, 261-289.

Paradis, C., Prunet, J.-F. (Eds.), 1991. The Special Status of Coronals: Internal and External Evidence. Academic Press, San Diego, CA.

Sagey, E., 1986. The Representation of Features and Relations in Nonlinear Phonology. MIT PhD dissertation, Cambridge MA.

Staun, J., 1983. Retraction of Old English [ææ] and bifurcation of Danish [a] and the articulatory gesture in dependency phonology. Lingua 59, 355-373.

Staun, J., 1996. On the locational description of consonants. Travaux du Cercle Linguistique de Copenhague XXIX.

van der Hulst, H., 1989. Atoms of segmental structure. Phonology 6, 2. 253-284.

van der Hulst, H., 1994. Radical CV Phonology: the locational gesture. UCL Working Papers in Linguistics 6, 439-478.

van der Hulst, H., 1995. Radical CV phonology: the categorial gesture. In: Durand, J., Katamba, F. (Eds.).

Wells, J.C., 1982. Accents of English, vol. 2, 3. Cambridge University Press, Cambridge. 